This report was prepared as an account of work sponsored by an agency of the United States Government. Neither the United States Government nor any agency thereof, nor any of their employees, makes any warranty, express or implied, or assumes any legal liability or responsibility for the accuracy, completeness, or usefulness of any information, apparatus, product, or process disclosed, or represents that its use would not infringe privately owned rights. Reference herein to any specific commercial product, process, or service by trade name, trademark, manufacturer, or otherwise does not necessarily constitute or imply its endorsement, recommendation, or favoring by the United States Government or any agency thereof. The views and opinions of authors expressed herein do not necessarily state or reflect those of the United States Government or any agency thereof.

PNNL-11006

UC-810

Project Technical Information

\section{Application of the HWVP Measurement Error Model and Feed Test Algorithms to Pilot Scale Feed Testing}

\author{
T.L. Adams
}

March 1996

Prepared for the U.S. Department of Energy under Contract DE-AC06-76RLO 1830

Pacific Northwest National Laboratory Operated for the U.S. Department of Energy by Battelle Memorial Institute
RECEIVED

MAR 261996

OSTI 
PNNL-11006

UC-810

Project Technical Information

\section{Application of the HWVP Measurement Error Model and Feed Test Algorithms to Pilot Scale Feed Testing}

T. L. Adams

March 1996

Prepared for

the U.S. Department of Energy

under Contract DE-AC06-76RLO 1830

Pacific Northwest National Laboratory

Richland, Washington 99352 


\title{
DISCLAIMER
}

This report was prepared as an account of work sponsored by an agency of the United States Government. Neither the United States Government nor any agency thereof, nor Battelle Memorial Institute, nor any of their employees, makes any warranty, express or implied, or assumes any legal liability or responsibility for the accuracy, completeness, or, usefulness of any information, apparatus, product, or process disclosed, or represents that its use would not infringe privately owned rights. Reference herein to any specific commercial product, process, or service by trade name, trademark, manufacturer, or otherwise does not necessarily constitute or imply its endorsement, recommendation, or favoring by the United States Government or any agency thereof, or Battelle Memorial Institute. The views and opinions of authors expressed herein do not necessarily state or reflect those of the United States Government or any agency thereof.

\section{PACIFIC NORTHWEST NATIONAL LABORATORY operated by \\ BATTELLE \\ for the \\ UNITED STATES DEPARTMENT OF ENERGY under Contract DE-AC06-76RLO 1830}

\author{
Printed in the United States of America \\ Available to DOE and DOE contractors from the \\ Office of Scientific and Technical information, P.O. Box 62, Oak Ridge, TN 37831; \\ prices available from (615) 576-8401.
}

Available to the public from the National Technical Information Service, U.S. Department of Commerce, 5285 Port Royal Rd., Springfield, VA 22161 


\section{SUMMARY}

In support of the Hanford Waste Vitrification Plant (HWVP), the Slurry Integrated Performance Testing (SIPT) subtask will perform full-scale testing of the Feed Preparation Test system (FPTS) currently located in the High Bay of the 324 Building in the Hanford 300 Area. The FPTS is an adaptation of the Defense Waste Processing Facility (DWPF) feed preparation system. The FPTS represents the proposed HWVP feed preparation system being designed by Fluor-Daniel, Inc. The equipment will be used to test the application of the DWPF design to the Hanford site waste feed.

Two important tasks of the HWVP product composition control (PCC) system are [Bryan and Piepel, 1992]:

(1) estimation of tank contents and uncertainties (expressed as covariance matrices), and

(2) controling the properties of the feed/melt/glass

A general Measurement Error Model (MEM) has been developed for the HWVP PCC system to estimate the contents and covariance matrices for both the source and recipient tanks after a transfer operation.

A preliminary version of the composition control algorithm; called the Frit Addition Algorithm (FAA) recommends the mass of fresh frit of known composition to transfer to the Slurry Mix Evaporator (SME) in order to maximize the waste loading subject to waste glass acceptability, and processability constraints. The FAA is a preliminary version of the SME Targeting Algorithm (STA), which chooses the target mixture for a single SME batch and recommends the masses of waste, recycle, and frit to transfer to the SME. A generalization of the STA, which extends the optimization to the selection of frit composition and reference mixture for an entire production campaign is also under development.

This document discusses the applicability of the HWVP PCC system MEM and FAA algorithms to estimation and composition control problems arising in the context of the FPTS. The existing algorithms are too specialized to be directly applicable to the FPTS. However, recommendations for generalizing these algorithms are presented which would improve their suitability for application to the FPTS.

With respect to estimation, it is important to recognize that the needs of the FPTS include continuous estimation and monitoring tasks in addition to the batch by batch updating used by the MEM. An approach to estimation that incorporates differential as well as algebraic constraints and which combines the advantages of batch processing using weighted squares techniques (as used in the MEM) and classical continuous estimation techniques (e.g., Kalman filtering) is proposed as a means for extending the MEM to the needs of the FPTS. The physical plant and operating procedures of 
the FPTS also differ from the HWVP. An object-ortented representation approach is proposed which facilitates the modular application of the existing MEM computer code to different structural and operational configurations.

Extensions of the FAA may find Iimited application in adjusting the composition of the feed simulants. However, the emphasis in the FPTS is on state estimation and parameter identification. For the most part, there is very little need for a composition optimization algorithm. For this reason, attention is focused in this report on 
SUMMARY ...................................iv

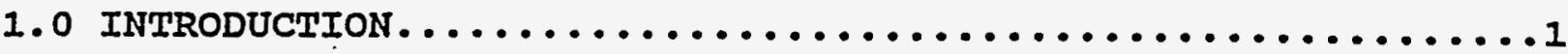

2.0 GENERAI DESCRIPTION OF EXISTING MEM AND FAA ALGORITHMS....5

3.0 DESCRIPTION OF FEED PREPARATION TEST SYSTEM............8

3.1 FPTS EQUIPMENT..........................

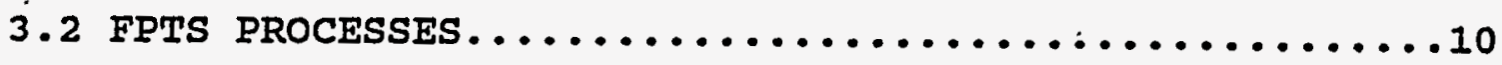

4.0 RECOMMENDED EXTENSIONS TO THE EXISTING MEM AND FAA

ALGORITHMS FOR USE IN THE FPTS..................13

5.0 CONCLUSIONS................................23

6.0 REFERENCES.................................26

APPENDIX A: General Discussion of the Use of Constrained

Weighted Least Squares for Data Reconciliation...28

APPENDIX B: HWVP Measurement Error Model Algorithm.........31

APPENDIX C: HWVP Frit Addition Algorithm.................. 35

APPENDIX D: Summary of SIPT Test Methodology..................

APPENDIX E: Basic Kalman Filter Equations...............43

APPENDIX F: Process Constraint Models..................48

APPENDIX G: Measurement Models.......................50

APPENDIX H: FPTS Monitored Variables...................54 


\subsection{INTRODUCTION}

The purpose of the feed preparation subsystem in the Hanford Waste Vitrification Plant (HWVP) is to provide for control of the properties of the slurry that are sent to the melter. The slurry properties are adjusted so that two classes of constraints are satisfied. Processability constraints guarantee that the process conditions required by the melter can be obtained. For example, there are processability constraints associated with electrical conductivity and viscosity. Acceptability constraints guarantee that the processed glass can be safely stored in a repository. An example of an acceptability constraint is the durability of the product glass.

The primary control focus for satisfying both processability and acceptability constraints is the composition of the slurry. The primary mechanism for adjusting the composition of the slurry is mixing the waste slurry with frit of known composition. Spent frit from canister decontamination is also recycled by adding it to the melter feed. A number of processes in addition to mixing are used to condition the waste slurry prior to melting, including evaporation and the addition of formic acid. These processes also have an effect on the feed composition.

In order to adjust the composition of the slurry by mixing with fresh frit, the composition of the slurry prior to mixing must be accurately known. Available measurements consist of chemical. analysis of samples extracted from the tanks at various stages of the processing and tank level and density measurements. The former yield estimates of the concentration of the various species. The latter provide estimates of the total mass, so that the concentrations may be scaled to determine the total amount of each species present. Because of noise in the measurement process, it is useful to adjust the measurements to agree with all known physical constraints, for example, the masses of all species in any given sample must sum to the total mass of the sample and the amount of mass transferred out of a source tank must be equal to the mass transferred into the receiving tank. The usual method for adjusting the measured values so as to minimize the sum of squares adjustment to the measured values while simultaneously satisfying the applicable constraints is known as data reconciliation. The measurement error model (MEM) is a data reconciliation algorithm for the concentration, level and density measurements and is used to obtain the best estimate of the slurry Mix Evaporator (SME) species concentrations prior to mixing with the fresh frit. This estimate is used by the Frit Addition Algorithm (FAA) to determine the amount of fresh frit to add. The MEM algorithm also produces a covariance matrix for these estimates so that the FAA can conservatively adjust for any error in the knowledge of the SME concentrations. The MEM is also used in the same manner to obtain updated estimates and covariances of the SME composition after mixing with the fresh frit. This composition estimate is used by 
the Feed Test Algorithm prior to sending the slurry to the melter.

The frit addition algorithm (FAA) uses the concentrations and uncertainties supplied by the MEM to determine the amount of frit to add to the SME to maximize the waste loading while at the same time increasing the probability that the processability and acceptability constraints will be met to statistically acceptable levels. The existing FAA assumes that the frit composition and associated error are known and that the composition is fixed a priori (i.e., the frit composition is not subject to optimization). The routine iterates on the amount of frit added and selects the maximum value that ensures (in the probabilistic sense) that none of the constraints will be violated.

Finally, the MEM is reapplied after fresh frit addition to produce an estimate of the. SME composition and associated uncertainty. The Feed Test Algorithm (FTA) is then applied to the MEM outputs in order to decide whether this particular batch is acceptable by comparing estimates of the SME composition and glass melt properties to the requirements (Bryan and Piepel, 1993).

The purpose of this study was to evaluate the appropriateness of the MEM and FAA developed for the full scale vitrification plant to the Slurry Integrated Performance Testing (SIPT) Feed Preparation Test System (FPTS). The SIPT FPTS is a test bed for obtaining data on the characterization of the equipment and processes to be used in the full scale plant using simulated, non-radioactive, waste slurries. In addition, the FPTS will ascertain whether certain assumptions needed to simplify the data analysis in the full scale plant (e.g... mixing produces a homogeneous slurry) are valid and will also characterize the measurement subsystems. In the full scale plant, various stages of the process take place in different tanks prior to being mixed. Raw waste is conditioned by the addition of formic acid and boiling in the slurry Receipt and Adjustment Tank (SRAT). The conditioned waste slurry and recycled waste stored in the Recycle Waste Collection Tank (RWCT) are added to the SME, where the composition of the melter feed is adjusted by the addition of fresh frit. In the SIPT FPTS, full scale operations are simulated in a single full scale test vessel in which all the processes performed by the SRAT, RWCT and SME are simulated in a sequential fashion in a single vessel. Therefore all the constituent processes can be measured and evaluated using a single test vessel. An additional half scale tank is provided for the preparation of slurries with the desired properties. Condensate from all thermal operations in the main test vessel is collected in an additional tank.

This study was carried out by first analyzing the methodologies used in the existing MEM and FAA algorithms. The equipment, processes, and measurements used in the SIPT FPTS were then characterized. The appropriateness of the MEM and FAA algorithms for use in the SIPT FPTS was then analyzed. The existing algorithms 
were found to be inadequate in their existing form. The primary reason for this mismatch is that the purpose of the original MEM and FAA algorithms is to obtain state estimates and control values for a highly structured configuration with known parameters, whereas the purpose of the SIPT FPTS is to obtain validation of equipment operation, estimates of the values of important parameters involved in the process, and verification of important assumptions used in data processing. Another important difference affecting the design of the estimation and optimization algorithms is the fact that the full scale plant makes use of batch processing based on data reconciliation, whereas the needs of the FPTS are better served by state estimation and parameter identification using real-time monitoring methods based on model reconciliation. By model reconciliation, it is meant that the parameters of the model are adjusted to minimize the squared state estimation error rather than adjusting the data to fit the model, as is done in data reconciliation.

The next phase of the study was to determine what modifications and extensions to the existing MEM and FAA algorithms could be suggested that might lead to their suitable application to the SIPT FPTS scenario. The major accomplishment has been to identify the important characteristics of the changes to the existing algorithms that must be addressed in further research and development in order to arrive at a suite of algorithms that is appropriate to the SIPT FPTS scenario. These recommendations for further investigations are specified in detail in section 4. A summary is provided here to provide perspective for reading the remainder of this report.

With respect to the MEM algorithm, we have found that the algorithm is specific to the HWVP plant and operational configuration. By using knowledge representation methods from object-oriented programming and artificial intelligence, it is possible to obtain a general purpose estimation and parameter identification algorithm that is suitable for a wide variety of waste processing scenarios. This approach would support generation of the state estimates and associated covariance matrices for a variety of plant and operational scenarios from a library of plant equipment and sensors. The actual configuration of equipment and sensors, and the estimation processes to be performed would be entered by the analysts, and the estimation algorithm would be constructed automatically from the library of process equipment and sensor behavioral models and generic templates for the estimation and optimization algorithms. By separating descriptions of processes, measurements, and algorithms a high degree of flexibility to different scenarios can be accomplished. This approach would not only facilitate extension of the MEM to the FPTS, but would also find application to a number of other applications in which continuous monitoring of chemical and physical processes is required. The current $M E M$ is also limited to mixing and evaporation processes and further assumes that the constraints must be satisfied exactly. BY extending the library of primitive processes 
and allowing for process noise, the range of processes that can be dealt with can be extended. This would permit the MEM to be extended to a wider range of applications and allow for soft matching of the process constraints. The existing measurement models assume that the noise is zero mean, additive and Gaussian. These models can be extended by providing parameterized models of bias and explicit models of the calibration processes. For example the dependence of the Holledge detection system tank levels on temperature can be explicitly accounted for. The existing MEM assumes that all constraints are algebraic in nature. This limits the applicability of the MEM to equilibrium states. By extending the MEM to include process dynamics, an algorithm incorporating both algebraic and differential constraints can be obtained. The batch nature of the existing MEM does not permit continuous monitoring of the process, which would be useful in the FPTS scenarios. In order to achieve detection of discrepancies at the incipient stage, an incremental, continuous monitoring approach is desired. Finally, there is no provision in the MEM for identifying gross errors and removing "baḍ data."

With respect to modifications to the FAA, there is no direct application of the FAA in the SIPT FPTS, since the FAA assumes only additions of frit of a fixed composition that is determined a priori and, hence, does not permit optimization over the current composition of the frit.. However, work done in developing and applying the Optimal Waste Loading (OWL) methodology [Hoza, 1993] provides extensions to the FAA which might find application in the FPTS. For example, OWL is being used to investigate blending of waste types, which might find application in the preparation of feed test slurries having the target composition. The mathematical optimization techniques used in owL may also find application in applying the FAA algorithm to the monitoring and control of chemical systems, for which the complete search of the entire domain of the control variables in discrete increments employed by the FAA may be impractical. 


\subsection{GENERAL DESCRIPTION OF EXISTING MEM AND FAA ALGORITHMS}

In order to provide a context for the discussion of the existing MEM and FAA algorithms, it is first necessary to describe the process sequence for feed preparation in the full scale plant. As previously mentioned, separate tanks are provided in the full scale plant for the preparation of waste slurry and spent frit. The contents of these tanks are transferred to the slurry Mix Evaporator (SME), where the composition is adjusted by adding an amount of fresh frit that balances the multiple objectives of high waste loading, slurry processability, and acceptable product glass characteristics. The slurry Receipt and Adjustment Tank (SRAT) and the Recycle Waste Collection Tank (RWCT) are assumed to be initially full. The slurry Mix Evaporator (SME) is initially empty. Inductively Coupled Plasma (ICP) samples are taken from the RWCT, the SME, and the SRAT. The level of the RWCT and SRAT and the level and specific gravity of the SME are also measured. The slurry in the SRAT is then transferred to the SME, and the level of the SRAT is remeasured. Next the liquid in the SME is removed by evaporation and the condensate is transferred.to the slurry Mix Evaporator Condensate Tank (SMECT). Spent frit is then transferred from the RWCT to the SME. The liquid content of the SME is again concentrated by boiling and the vapor contents transferred to the SMECT. More spent frit is then added to the SME from the RWCT. Inductively Coupled Plasma (ICP) samples are again taken from the RWCT and the SME and the level of the RWCT and the level and density of the SME are remeasured.

The Measurement Error Model is now applied to the six measurement sets (three tanks in each of two states (empty and full) and the NOXIDE + 5, where NOXIDE is the number of species present in the mixture, constraint equations to determine the best estimate of the contents of the SME. These constraints represent the overall net mass change in the SME (mass change in SME = mass transferred from RWCT + mass transferred from the SRAT - mass evaporated to the SMECT), the four mass balances (RWCT FULI, SRAT FULL, SME EMPTY, SME FULL) obtained from the requirement that the ICP sample mass must equal the sum of the constituent component masses, and the NOXIDE mass balances that represent the fact that the masses of each species must also conserve mass in the same way as the overall mass. The measurement sets for each of the tank samples all contain a level measurement (a total of six individual measurements). For FULL tank samples from the RWCT and SRAT, the measurement set also includes a set of oxide mass measurements for each species, the mass of the sample that is analyzed by ICP, and the weight of the sample removed from the tank (a total of 12 individual measurements for each of 2 FULL samples). The SME measurements contain an additional specific gravity measurement but are equivalent in other respects to the measurements from the other two tanks in both EMPTY and FULL states (a total of 13 samples for each of the 2 SME fill states), bringing the size of the complete measurement vector to 56 $(=6+24+26)$. 
The SME composition estimates are then used by the frit addition algorithm (FAA) to determine the amount. of fresh process frit to add from the Process Frit Slurry Feed Tank (PFSFT). The existing FAA adds the minimum amount of fresh frit (maximizes the waste loading) such that neither the 2 constraints on the processability (electrical conductivity, viscosity) nor any of the 3 constraints on the durability (B release, Ii release, $\mathrm{Na}$ release) of the vitrified glass are violated. The existing FAA uses a straightforward search through a set of quantized levels of added frit that spans the amount that can be added without overflowing the SME in uniform increments of added mass. The algorithm determines the uncertainty of each of the five properties (as a function of frit being added) by considering errors associated with frit composition, level measurements in the SME, composition in the SME, and property coefficients. The maximum (over all five properties) of the minimum frit addition that does not violate the constraints (for each property on an individual basis) is selected as the actual amount of frit to be added. Constraint violation is defined as a limit on the probability that the actual value of the property will not exceed specified limits.

The liquid is again removed from the SME by evaporation. Level and species concentration measurements are then obtained from the PFSFT and the SME. Process frit in the amount determined by the FAA is then transferred to the SME. The level and species concentrations are remeasured. The MEM is then applied to the set of measurements obtained from the FULI and EMPTY PFSFT and SME to obtain the best estimates of the PFSFT and SME levels and concentrations.

The MEM algorithm is essentially a data reconciliation algorithm and can easily be generalized for applications in situations where it is desired to find the best set of adjustments to a set of data which are known to fit a set of algebraic constraints. Appendix A discusses the general. form of the data reconciliation problem. Appendix B gives the constraint models and the gradient matrices which are required by the algorithm for the full scale process sequence described above.

Adjustment of the HWVP feed composition takes place in two stages [Bryan and Piepel, 1993]. The Glass Formulation Algorithm (GFA) selects the frit composition for an entire production campaign. The SME Targeting algorithm (STA) chooses the target mixture for a single SME batch and recommends the masses of waste, recycle, and frit to transfer to the SME. The FAA is a preliminary version of the STA that adjusts only the amount of fresh frit of a known composition to be added to the contents of the SME. The FAA can be generally expressed. as a minimization problem subject to probabilistic constraints. The existing algorithm is specialized and takes advantage of many special characteristics of the specific problem it addresses; the one dimensional minimization, the limited range of feasible values, and the low resolution required of the solution permit a full search of the space of possible solutions, 
so that formal optimization techniques are not required. Independent research on optimal waste loading under a wider range of feasible inputs (individual optimization of each component of the fresh frit) is under consideration under another task in this project [Hoza, 1993]. The specification of the problem that the existing frit algorithm addresses and a summary of the algorithm are given in Appendix $c$.

The purpose of this report is to identify potential applications of data reconclilation and optimization typified by the MEM and FAA to the pilot plant and to determine what extensions of these algorithms might be worth pursuing for the pilot plant application. section 3.0 gives a brief review of the process sequences, available measurements, and objectives of the FPTS. Section 4.0 discusses extensions of the existing algorithms that are required to meet the needs presented in section 3.0 . 


\subsection{DESCRIPTION OF FEED PREPARATION TEST SYSTEM}

\subsection{FPTS EOUIPMENT}

The Hanford Waste Vitrification Plant (HWVP) Feed Preparation Test System (FPTS) is an adaptation of the Defense Waste Processing Facility (DWPF) feed preparation system. The equipment will be used to test the application of the DWPF design to the Hanford site waste feed. The HWVP FPTS consists of a vessel (evaporator), heat transfer coils, condenser, slurry transfer/melter feed pump, sample pump, sample system, agitator, Holledge-Ievel Detection/Density Measurement system, and supporting monitoring and control equipment.

Vessel $\mathrm{HB}-15$ is a full-scale representation of the three feed preparation process tanks:

(1) Slurry Receipt and Adjustment Tank (SRAT)

(2) Slurry Mix Evaporator (SME), and

(3) Melter Feed Tank (MFT).

The HWVP SRAT is designed to receive, concentrate and formate HWVP feed. Feed slurry is pumped to the SRAT, cooled, and sampled in order to identify the composition and ensure adequate mixing. The feed is then concentrated by boiling the slurry and evaporating to a predetermined solids concentration (nominally 140 grams of total oxides per liter of slurry). Formic acid is added at an, elevated temperature and the batch is then digested at boiling temperature. The formic acid addition reduces the yield stress and viscosity of the slurry and provides the melt reductant to inhibit foaming in the melter.

Recycle Waste and Process Frit are added to the formated slurry in the SME. Adjustments are also made at this point to ensure that the melter feed conforms to the total target oxide concentration (nominally 500 grams of test oxide per liter of melter feed). The total oxide concentration is controlled by the amount of frit added to the formated slurry and the volume of feed in the test vessel. The redox state is adjusted by the addition of a known amount of formic acid and/or sugar, if required. Following adjustment of total oxide concentration and redox state, the slurry is cooled and sampled in preparation to being sent to the MFT.

The HWVP MFT receives the prepared feed from the sME. The melter feed is maintained in a well-mixed state by constant agitation. The MFT will also provide cooling of the contents. The feed is then transferred into the melter through two independent melter feed delivery systems.

Temperature control of $\mathrm{HB}-15$ is provided by three concentric heat transfer coils suspended from the vessel head. The inner coil is for cooling water and the midale and outer coils are for steam 
heating.

Condenser $C D-1000$ is a full scale representation of the DWPF SRAT/SME condenser. Slurry Mix Evaporator Condensate Tank HB-14 is used to collect the condensate from the condenser on HB-15 during normal operations.

Transfer/Melter Feed Pump P-1101 is a cantilevered centrifugal pump that is used:

(1) to transfer feed out of the vessel HB-15 during SRAT/SME operations, and

(2) to supply feed to the melter through a recycle loop during MFT operations.

The Hydragard Sampler is an in-line, closed-1oop, liquid sampling system designed to provide positive extraction and collection of samples from the process vessel (HB-15) using a diaphragm pump. The sample is used to characterize the feed composition. Sample-pump P1002 is used to circulate slurry through the sample system and is similar in construction to the transfer pump.

The auxiliary sampler system installed in Tank HB-15 has the capability of drawing samples from seven (7) different levels within $\mathrm{HB}-15$. These samples will be used to verify the homogeneity of the feed slurry in comparison to the samples taken using the main sample pump.

Agitator AG-1000 has two impellers mounted on a single shaft, a radial flow impeller and an axial flow impeller, and is driven by a variable speed electric motor.

The Holledge Level Detector works on the same principle as a dip tube bubbler. Tubes are set at different elevations above the floor of the tank, which causes a change in pressure on the air flowing into each tube that is dependent on the liquid level in the tank. The difference in pressures between the tubes is then translated into level and specific gravity measurements. In addition to the Holledge Level Detection System, a conventional dip-tube bubbler system has been installed into $\mathrm{HB}-15$. The diptube bubbler is used as a comparison against the Holledge Level Detector and to provide a backup in the event that the Holledge Level Detector fails.

There is an air-cooled camera installed in HB-15 that provides the ability to view the inside of the tank during operations.

Receipt and Iag storage Tank $\mathrm{HB}-13$ is an existing tank that will be used for make-up of both feed and frit slurries and for transfer pump testing. Weigh Tank TK-900 is used as a chemical addition station to $\mathrm{HB}-15$ and to collect condensate from the condenser. Weigh Tank TK-900 is equipped with an air operated diaphragm pump which will be used to transfer solutions to the process tanks. 
Approximately 70 process variables are monitored throughout the process, primarily flow rates, pressures, and temperatures. The current, voltage and speed of the agitator, the sample pump and the transfer pump are also monitored. Liquid Ievels in $\mathrm{HB}-14$ and $\mathrm{HB}-15$, specific gravity in $\mathrm{HB}-15$ and weight in $\mathrm{TK}-900$ and $\mathrm{HB}-15$ are also available: $\mathrm{HB}-14$ is equipped with a $\mathrm{pH}$ meter.

Some of these data are used for process control. Others are simply collected for analysis purposes by the data acquisition system.

\subsection{FPTS PROCESSES}

The test plan for the pilot feed (HWVP, 1991) consists of essentially three phases, one for each of the three tanks involved in the full scale process:

(1) Slurry Receipt and Adjustment Tank (SRAT) Simulant Processing,

(2) Slurry Mix Evaporator (SME) Simulant Processing, and

(3) Melter Feed Tank (MFT) Simulant Processing.

The general purposes of each phase are to simulate and characterize the corresponding feeds and operations of the full scale process.

Each of the top-level phases can also be subdivided into sub-phases that are associated with the activities that take place in the respective tanks. For SRAT simulant Processing, the subphases are

(1) Simulant Preparation,

(2) Simulant Concentration (Heating, Boiling, and cooling), and

(3) Formic Acid Addition and Reaction.

SME Simulant Processing can be subdivided into two sub-phases:

(1) Recycle Waste Addition, and

(2) Process Frit Addition.

MFT Simulant Processing is beyond the scope of this study.

Within each sub-phase a number of processes and tests are performed. A detailed description of the processes and tests to be performed by the FPTS has been extracted from the test plan and is presented in Appendix D. In this section we briefly describe from a general perspective the classes of processes and tests involved. The purpose of describing the tests and processes in this way is not only to simplify the discussion but also to facilitate the basic task of this study--to identify applications of the MEM and frit addition algorithms to pilot plant operations and to specify modifications and extensions that would be required by the new applications.

The basic categories of processes involved are: 
(1) Simulant Preparation

(2) Mass Transfer and Mixing

(3) Dilution

(4) Thermal Processes (Boiling, Cooling, Evaporation, Heating)

(5) Formic Acid Adaition

The MEM algorithm deals explicitly only with mass transfer and mixing and evaporation. The Frit Addition Algorithm deals explicitly with the determination of the amount of one feed stream to add to another such that the mixture composition satisfies certain constraints and therefore may have application to simulant preparation and mass transfer and mixing processes.

The basic classes of tests involved are:

(1) Homogeneity Tests

(2) Equipment Performance Evaluations

(3) Coil/Condenser Tests

(4) Simulant Characterization

(5) Offgas Analysis

The objectives of the homogeneity testing are to determine the ability of the equipment to produce a homogeneous slurry and to evaluate the ability of the Hydragard sampler to collect a representative sample.

At major slurry compositions (dilute HWVP feed, concentrated HWVP feed, formated HWVP feed, and HWVP melter feed) selected equipment performance evaluations are carried out such as pump performance, sampling, slurry transfer, and Holledge system measurements.

The coil/condenser tests are designed to characterize the performance of the evaporator/condenser as a function of liquid level, slurry concentration, and boiling rate. Two condensate samples per steam flow rate will be taken from the condensate line during each test to determine solids carryover in the condensate. An aerosol sample will also be taken during each test to determine the solids carryover in the off-gas line.

Simulant compositions are characterized by performing ICP (Inductively Coupled Plasma), atomic absorption (cesium), ion chromatography (fluoride, chlorine, nitrate, nitrite, sulfate, formate, and phosphate) and ion selective electrode (ammonia) and redox (formated feed only) measurements. Weight percent total solids, weight percent total oxides, $\mathrm{pH}$, density, viscosity and solids settling rate analyses will be performed on the slurries to identify their physical properties.

Off-gas composition analysis will be employed to characterize the generation rates of the major gaseous reaction products. Specifically the temporal emission rate behavior of $\mathrm{NO}_{x /} \mathrm{N}_{2} \mathrm{O}$, $\mathrm{NH}_{3}$, 


$$
\vdots
$$

$\mathrm{O}_{2}, \mathrm{~N}_{2}, \mathrm{H}_{2}, \mathrm{CO}$, and $\mathrm{CO}_{2}$ will be continuously monitored with specific gas analyzers. Hydrogen gas emissions will be monitored during all feed preparation steps due to the flammability hazards it presents.

The existing MEM algorithm addresses only the simulant characterization test, that is, the purpose of the MEM is to obtain the best estimates of the species concentrations, given all the available measurements. 


\subsection{RECOMMENDED EXTENSIONS TO THE EXISTING MEM AND FAA}

\section{ALGORITHMS FOR USE IN THE FPTS}

In considering the applicability of the FAA- and MEM to the FPTS, the differences in the objectives of full scale operations and feed performance testing must be taken into account. In the case of full scale operations, the primary objectives are accurate and precise estimation of composition and statistical process control of feed composition. The MEM contributes to this objective by providing improved estimates of the feed composition prior to frit addition and verification of feed composition after frit addition. The FAA contributes to this objective by determining the minimum amount of frit that must be added to ensure processability of the slurry and acceptability of the vitrified waste.

In the case of feed performance testing, the focus is more on characterizing the properties of the siurry, verifying certain assumptions made in the process models (e.g., that mixing produces a homogeneous slurry), obtaining unknown coefficients of the process models (e.g., condenser heat transfer coefficient), verifying equipment models, and monitoring process variables for safe operation. The FPTS is equipped with additional instrumentation for these purposes, including spatial sampling of the composition of the slurry, off-gas analyses, and pump and agitator electrical and speed monitors. The instrumentation provided in the pilot plant is therefore capable of giving a much more comprehensive view of processes and operations than can be provided with the instrumentation available in the full scale plant. Because extension of the FAA for the full scale plant is currently under study. (see for e.g., (Bryan and Piepel, 1993) and (Hoza, 1993)), most of our discussion is directed at extending the MEM. However, the use of object-oriented representation techniques and state space modeling strategies can be equally employed in process optimization algorithms (of which the FAA is a very special case) in the same way that they are illustrated here in the context of estimation and parameter identification algorithms (of which the MEM is a very special case).

In the following paragraphs, our purpose is to generalize the MEM algorithm along several directions. A few observations about the form of the MEM motivate our discussion of these extensions. The first observation is that the algorithm is completely determined by the form of the process constraints, the form of the measurement equations and the covariance matrix of the measurement noise. Gradient matrices required by the MEM are generated by differentiating the constraints with. respect to measured or unmeasured variables. The first set of recommended changes to the algorithm therefore deals with facilitating the construction of the algorithm by making use of object-oriented representation methods. The central idea is to decompose the physical plant into a set of more primitive descriptions representing the primitive plant equipment and sensing devices. The global behavior of a specific 
plant is then synthesized by specifying separately the plant objects (primitive plant equipment and sensors) from a library of generic equipment and sensor models and the plant topology (interconnections among the components and placement of sensors) by specifying which outputs of each object are connected to which inputs of other objects. The combination of primitive objects and interconnections describes the physical layout of the plant and is essentially equivalent to the chemical engineer's piping and instrument diagram. Since the state of the plant is determined not only by its physical configuration but also by how it is operated, it is necessary to augment the object and interconnection models by another set of models describing how the plant will be operated. The description of plant operations can be decomposed into a library of primitive actions (eg., open a valve) in the same way that the physical plant was decomposed into a set of tangible primitive objects. The global description of action includes the temporal sequencing of the primitive actions in the same way that the global description of physical layout includes the description of interconnections. It is also possible to model event-driven actions by augmenting the primitive action models with the appropriate activation preconditions. A process becomes active when the preconditions become true in any operational scenario. The temporally-sequenced and event-conditional description of the actions to be performed constitutes the process model. The behavior of the plant can be predicted given the plant and process models. The observed behavior is then predicted from the measurement models which describe the relationship between actual and observed behavior:

Summarizing the above discussion, the object-oriented method can be described as a decomposition of behavior in terms of both the physical structure of components and the temporal structure of action. The plant physical structure is hierarchically decomposed into a set of component equipment each of which is described by behavioral models that depend on external parameters specifying links to behaviors of other components and links to active processes and internal parameters that describe conditions (e.g., pressure, temperature) particular to that component. plant operational procedure is decomposed temporally into a sequence of primitive process that are activated either manually, by the occurrence of specific events in the operational scenario, or by automatic control systems. The sequence of primitive processes triggers behavioral constraints to be active or inactive during specific time frames, which imposes a different set of constraints to be active between operational events. The global behavior of the plant is obtained from the collection of constraints describing component behaviors,' component interconnections, and active processes.

The reformulation of the algorithm in general object/process terms allows the algorithm to be applied more readily to novel combinations of process sequencing and measurement configurations. 
In particular this means that the modified MEM can be used for various state estimation tasks required by the FPTS. FPTS operations differ from the full scale operation. with respect to process and measurement configuration and process sequencing scenario. The object/process approach also permits the development of estimation algorithms like the MEM to be decomposed. The first step consists of describing the set of constraints that apply during a particular interval of time. The second step consists of constructing the estimation algorithm from the given plant physical configuration and operational sequences. The benefits of this approach are the ease with which the estimation algorithm can be applied to a wide variety of plant configurations and flexibility to changes in operational procedures that may arise.

The goal of the algorithm development described here is to provide the framework for an object-oriented estimation environment that can produce a complete state estimate and associated covariances given a description of:

(1) the plant configuration specified as a set of unit processing elements and their interconnections,

(2) a set of measurements specified by the appropriate transformation of plant states and a description of the measurement errors, and

(3) a process scenario consisting of a. temporally related set of primitive operations that specify the constraints that must hold for a specific subset of the states during a particular interval of time.

For the FPTS special case, the process elements consist of the tanks and pumps used to transfer material, the measurements consist of the various masses, volumes and concentrations that are monitored, and the process scenario consists of the various tank transfers, chemical additions, and dilution and concentration operations that are specified in the test plan. The measurement scenario consists of the description of the measurement types that are available and the sampling description (how often sensed values are obtained). The state estimation algorithm is recursive. A state update equation is provided to project the effects of the current process operation on the values and uncertainties of the state variables. The state update algorithm is essentially a simulator for the mean value of the system state and an algorithm to keep track of the state uncertainties. A measurement update algorithm is provided to incorporate the effects of measurements on the estimates and their covariances.

In the following paragraphs, the elements of the object-oriented approach to equipment and process modeling are described in somewhat more detail. It is assumed that a library of primitive equipment describing their behaviors in generic terms and a library 
of primitive actions describing the effect of activation of these actions on the primitive objects is available. An element of either library can be introduced into the model of the plant scenario by instantiating an element from the 1ibrary. Instantiation may be described as introducing the set of constraints associated with that action or process into the global model and explicitly stating the values of parameters that may be expressed generally in the model libraries. For example a Tank 1 instance may be created from the generic tank library by specifying what kind of tank it is (e.g., cylindrical) and giving values to its cross-sectional-area and height. The physical model of the test facility is synthesized by instantiating specific model entities from a library of component model templates. The plant physical model is then completed by specifying the interconnections and other causal pathways between the instantiated components. The model of the test plan is composed in a similar fashion as a sequence of primitive operations selected from a library of generic process methods. The generic process methods may influence the behaviors of the components and require certain constraints to be in effect while they are active. Each of the elements of this description is elaborated on in the sections below.

\section{plant Model}

The plant model consists of a set of interconnected equipment models which collectively define the possible behaviors of the plant. The individual equipment models describe the possible local behaviors of the components of the system in terms of constraints that must be satisfied in any valid global solution. For example, the sum of the masses of the components of a multicomponent solution in a tank must be equal to the total mass contained in the tank. The connectedness models describe any interactions that may occur among the components. For example, if there is a pipe connecting two tanks and the conditions for flow are satisfied (gravity gradient or pump), then the amount of material flowing out of one tank must be equal to. the amount of material flowing into the other tank and the rate of flow at the output of the discharging tank is equal to the rate of flow at the input to the receiving tank. Individual components are instantiated from a general library of component templates. The component templates determine the general form of the component behaviors and the component instances give specific details of a particular component in the plant scenario, for example, an instance may specify the values of parameters given in the class template.

\section{Component Prototype Models}

Component prototypes are the templates for objects used in the scenario. Each prototype has associated with it a number of attributes each of which may contain the description of a parameter or which may contain pointers to other prototypes which contain a more detailed description of the slot. This dual description of 
attributes in terms of simple values or more complex objects permits the description to be abstracted to the appropriate level of detail. The parameter description is a primitive prototype that contains the name of the parameter, a time history of its values, the units used for specifying that parameter, pointers to any constraints in which that parameter appears, mathematical descriptions of the parameter and any procedures that may be used to evaluate the parameter. Permitting pointers to other prototypes to be used as slot fillers permits the objects to be defined hierarchically. For example, a reaction vessel may consist of the tank containing the reactants, the agitator for stirring the reactants, and heating and cooling coils for controlling the temperature of the reactor. The state of a component is a set of parameters that is sufficient to give a complete description of the component's behavior. The prototype may contain additional -descriptors of the component that are derivable from the component state if desired. For example, if the tank geometry is described in terms of a discrete parameter giving its shape as cylindrical, then its cross-sectional area and length are sufficient to describe its geometry, but the prototype may contain a slot for volume as well. In this case the consistency of the redundant constraints must be maintained.

\section{Component Instance Models}

Component instance models are defined as instances of component prototype models. Component prototype models specify the parameters and behaviors of the components in general terms. Component instance models specify the specific values of parameters of a specific component in the scenario. For example a component prototype model may define the generic description of a tank or a valve. The component instance model describes a particular tank or valve in the scenario, for example, Tank HB-14, a stainless steel tank that is the primary receiver for condensate generated from SRAT/SME operations. .

\section{Connectedness Models}

Connectedness models describe the various interactions that can take place between the components. The most common example of connectedness in chemical systems is the piping between the various components through which materials transfer takes place. Connectedness constraints are the basic mechanism through which local behaviors may impact global behaviors of the system. The primary connectedness constraint for the SIPT is the pipe. A pipe establishes the equality of the mass and mass flow rates at the ports to which it is connected.

\section{Process Model}

The process model consists of a set of local activities that are applied to the plant model in order modify its global behavior to 
achieve some specified set of objectives. Local process activities modify the parameters of a particular object over a particular time interval. The local activities may be performed in series or in parallel. The complete set of activities for each component over the entire time span of interest is called the process scenario. For example, a tank-to-tank transfer consists of changing the state of the valve in a pipeline connecting the tanks from open to closed for a specified interval of time or until some particulax constraint is met. For example the source tank may become empty at some point in time, thereby causing the flow to cease.

The global behavior of the plant is predicted by propagating the consequences of the local actions throughout the entire plant and over the duration of the scenario. The algorithm which projects the current estimated state forward in time to account for the dynamics of the system and any control activities that occur during that interval is called the process update algorithm. The process update algorithm updates both the values of the components comprising the plant and their associated uncertainties.

\section{Measurement Model}

The measurement model consists of a set of constraints that describe the measured variables in terms of the process states and any errors that are associated with the measurement. A typical measurement equation thus takes the form:

$z_{1}=f\left(x_{1}, x_{2}, \ldots, x_{a}\right)+e_{i}$

where $f\left(x_{1}, x_{2}, \ldots, x_{n}\right)$, represents the deterministic aspects of the transformation of the system state performed by the measuring device and $e_{i}$ represents the measurement error. $e_{i}$ may consist entirely of random error, in which case it is described by its probability distribution, its temporal correlation and its correlation with other random variables in the system. Additional structure may be imposed on the error, if desired. For example, a measured value which is nominally constant, but which has an unknown quadratic drift over time may be written as:

$e_{1}=\left(b_{0}\right)_{1}+\left(b_{1}\right)_{1} * t+\left(b_{2}\right)_{1} * t^{2}+n_{1}$

where $\left(b_{j}\right)_{i} j=0,1,2$ are constant but unknown parameters and $n_{l}$ is random noise. A similar expression can be used to represent the unknown relationship between level and temperature in the Holledge Level Detection system. Temperature measurements can then be used to estimate the unknown coefficients in the model in order to calibrate the system.

In the object-oriented representation of the plant, sensor instances will be selected from a library of sensor prototypes. For each sensor prototype the form of the function $f\left(x_{1}, x_{2}, \ldots, x_{n}\right)$ is 
given. Every sensor also has a sampling history, which describes the time at which measurements are taken (either as sampling rates, sample at specific events in the process, or a specific function of time), a measurement noise description, and a calibration method.

The second set of extensions to the MEM algorithm results from comparing the form of the constraints in the kalman filter with those in the constrained weighted least squares algorithm. The Kalman filter is a well known algorlthm for obtaining minimum mean squared error estimates in dynamic systems modeled by constraints expressed as differential equations that is analogous to the weighted least squares solution for static systems modeled by algebraic constraints. A brief review of the Kalman filter equations for discrete time systems is presented in Appendix $\mathrm{E}$.

In the Kalman filter, there are two distinct sets of equations, the process model equations, given by equation $\mathrm{E}-1$, and the measurement equations, given by equation E-2. In the MEM, the process states are converted to measurement variables (by substituting any relations of the form $\mathrm{E}-2$ into the process state equations) so that all measurement variables appear in the state equations. Any unmeasured process states remaining after substitution become unmeasured variables and are treated differently by the algorithm.

Three extensions to the approach adopted in the MEM are suggested by the comparison of the different representations used in the Kalman filter and the MEM. First, it is desirable to modularize the description, eliminating any coupling that might occur between the description of the process constraints and the description of the measurement constraints. This facilitates maintaining a clear distinction between sources of error that arise from lack of understanding of the underlying chemical and physical processes and any error arising from errors in the measurement process. Second, a convenient method for introducing "soft matching" of the process constraints is desired. It is frequently the case that the constraints will be satisfied only inexactly, for example, the compositions may change due to unmodeled chemical reactions as well as mixing during mass transfer. Therefore, the mass of a particular species after mixing may not be exactly equal to the sum of the masses of that species from the two streams being mixed, since a small amount of that species may be converted to some other species. If the reaction converts a significant fraction of the species, then it may be necessary to explicitly model the reaction as an additional constraint. However, if only a small fraction will be converted, it may be adequate to simply model the error as process noise. The process noise levels may be adjusted to reflect the a priori knowledge of the tendency of this species to be modified in the mixture. In the literature on regression with algebraic constraints (see, for example, Fuller (1987)), the approach to dealing. With process noise is to introduce an intermediate and unobservable variable when defining the 
regression, the so-called latent variable, $x_{1}$, and then define an additional noisy algebraic constraint that defines the observed, or manifest variable, $x_{l}$, in terms of the latent variable. Models with fixed latent variable are called functional models, while models with random latent variable are called structural models. For example, if it is desired to define a structural model for an inexact Iinear regression, we obtain

$$
Y_{t}=\beta_{0}+\beta_{1} x_{t}+e_{t}, t=1, \ldots, \pi
$$

for the "process model" with $e_{t}$ representing the process noise, and

$$
x_{t}=x_{t}+u_{t}
$$

for the "measurement model", with $u_{t}$ representing the measurement noise.

Equations 4.3 and 4.4 are in a form very similar to the constraints used in the Kalman filter formulation except that, in the algebraic case, the constraints are global, in the sense that the linear fit described in equation. 4.3 applies to the entire set of data, whereas in the Kalman filter the constraints are local, in the sense that only the instantaneous rate of change of state is constrained. In the Kalman filter, the state estimates are adjusted to fit the data, whereas, in the MEM the data are adjusted to fit the model. The former approach may give better indications of the quality of the model, whereas the latter may be more useful in identifying "bad data." For the FPTS, an approach more suited to model reconciliation is desired.

Three explicit recommendations with respect to specification of the constraint equations derive from the above considerations. The first recommendation is that the state variables to be estimated should reflect parameters defining process behavior, not observations. For the pilot plant algorithms, a convenient set of state variables is the concentration of each species in each vessel. The second recommendation is that process constraints and measurement constraints be kept distinct so that process dynamics and process observation can be specified independently. our third recommendation is that, all state variables should be considered as functions of time so that state histories can be maintained over a sequence of operational processes.

Data reconciliation algorithms have considered only algebraic process constraints, whereas Kalman filter approaches have considered only differential equation constraints. An approach is needed for the FPTS algorithm that permits state estimation for hybrid representations containing both algebraic and differential 
constraints. The Kalman filter approach traditionally makes strong assumptions regarding linearity and staționarity of the process. The extended Kalman filter and second-order KaIman filters have been developed for dealing with nonlinear constraints, but rely on linearization about a reference trajectory or the previous prediction. Techniques also exist for dealing with abrupt changes in the process equations that occur at process event times, for example, process noise tuning, adaptive estimation of the process noise matrix, and parallel filters matched to a set of discrete models. Kalman filter techniques are most appropriate for smoothing high sampling-rate measurements with respect to a process model. In the FPTS, measurements related to overall mass balance, such as level and density, are made at sufficiently high rates for the Kalman filter approach, but composition related measurements are obtained infrequently, since they require substantial offline analysis. Therefore any approach based on Kalman filtering would have to deal with potentialiy large discrepancies between predicted and measured compositions at the infrequent composition measurement updates. This situation is somewhat analogous to the position updating of inertial navigation systems, in which the long term position drift of the accelerometers is corrected by a position update from a system with accurate instantaneous position measurements, such as the global positioning satellite system. The nonlinear regression techniques deal with nonlinearity by iteration. The potential problems include the possibility of many local minima and speed of convergence. It appears that a hybrid technique that retains. the Kalman filter extrapolation method for state prediction between composition measurements and an iterative approach to measurement updates at the composition sampling times may provide the advantages of -both approaches.

Another limitation of the existing MEM is the restriction of the process constraints to mass balances. Extensions of the data reconciliation approach that deal with energy balance for a single flash operation are described in MacDonald and Howatt (1988). This paper also includes flow rates, pressures and temperatures in the state vector. A Kalman filter for the estimation of reaction rates that includes process in the mass balance equation, uses a random walk model for the reaction rate is described in (Elicabe and Georgakis, 1992). The proposed scheme in the latter paper assumes the availability of on-line measurements of overall concentrations of the reactants, and the lack of knowledge on the reaction rate dependence with those concentrations. A state space description of systems characterized by a set of m reactions involving a set of $n$ components, which considers both reaction kinetics and exchange dynamics is developed in (Bastin and Lévine, 1993). Extending the library of process models for the MEM would reduce the uncertainty in the melter composition estimate and increase the fundamental understanding of chemical processes in the feed system.

The existing MEM is written in batch form. The algorithm processes all the measurements simultaneously in a single iterative pass. The 
size of the matrices involved in the algorithm increases directly with the number of measurements. The Kalman filter uses an incremental approach in which the state is projected and updated at each instant in time. This limits the size of the matrices to the number of variables that are necessary to describe the system at a single instant of time. A theoretical problem for the incremental approach for nonlinear systems is that the optimality of the recursive approach depends upon the fact that the current state estimate is a sufficient statistic for the past data, which in turn depends on the linearity and Gaussian assumptions. However, approximations using the recursive structure have been successfully applied to nonlinear systems. The incremental approach is especially desirable for the FPTS algorithm, since a large number of processes is sequenced through the same small set of equipment. 


\subsection{CONCLUSIONS}

This section describes the recommendations for modifications and extensions to the existing measurement error model (MEM) and frit addition algorithm (FAA) that would permit the concepts embodied in these codes to be applied to the test and evaluation environment of the FPTS. In addition to the state estimation. and optimization tasks performed by the MEM and the FAA, respectively, there is also a need to employ the same fundamental process and measurement models to additional tasks, such as parameter identification, realtime monitoring and control, and data and model reconciliation. The results of our preliminary study suggest that the development of an integrated environment that can perform all these tasks within a common problem-solving framework, utilizing a library of generic equipment and process models is highly desirable. Use of this model-based approach facilitates code transportability and reuse throughout the scale-up process and is robust with respect to changes in the configuration and operating characteristics of the target full scale facility. This approach also facilitates incremental development of the algorithms, so that the number of necessary assumptions required can be gradually reduced, thus enhancing the range of applications to which they can be applied.

A summary of our recommendations for modifications to the existing algorithm include:

(1) Implement the code in an environment that facilitates reapplication of the algorithms to a variety of plant configurations and operational scenarios. Prototype the code in an object-oriented environment that facilitates the development a general library of equipments (e.g.,-melters, tanks), a library of fundamental processes (e.g., mass transfer, mixing, reaction), a library of measurement sensors (e.g. tank level, species concentration) and their associated error models (biases, calibrations, covariance matrices). The library component models can be used to configure the plant model by mirroring the particular piping and instrumentation diagram and operations schedule (in the case of the full plant) or test methodology (in the case of the FPTS). The operations schedule may be event-driven. For example, it may be desired to sample a tank after. it reaches some specific level; empty or full. This is accommodated by augmenting the primitive processes with a set of activation constraints, which determine the conditions under which a particular process may become active. To implement an algorithm for a particular configuration (e.g., full-scale, FPTS), the appropriate components from the library are instantiated and connected according to the piping diagram, sensors are instantiated from the measurement models and placed according to the instrumentation diagram, and plant operations are instantiated as a schedule of fundamental processes from the process library. The appropriate methods for the task at hand (parameter identification, simulation, state estimation, optimization) can then be assembled 
from the appropriate state descriptions of the composite model.

(2) Strictly enforce separation of the process description and the measurement description. The process model consists of a description of the normal behavior of the plant in terms of set of algebraic and differential constraints that must be satisfied (e.g., energy and mass balance), random modeling error (usually in terms of covariance matrices on the process state variables), and any systematic process error (e.g., leaks) that may be present. The measurement error model consists of a description of the desired transfer function between the variables describing the process state and the measured variables (e.g. tank levels are expressed as a function of measured pressures), any bias (e.g., temperature drift) and random errors that may be present, and the consequences of any calibration schemes that may be employed.

(3) Use representations that facilitate the joint consideration of steady state (e.g., mass balance) and dynamic (e.g. integration of flow rate to obtain total flow) constraints. In most applications differential as well as algebraic constraints must be satisfied. This approach has become standard in flowsheet-oriented simulation environments (see for example, Bar et al, (1993)). The HWvP plant simulation code also permits the use of both algebraic and differential constraints. (Kuhn, 1992).

(4) Extend the library of process models. The MEM algorithm is currently capable of modeling only tank transfers. A wider range of process models would permit the MEM to be applied to a more diverse set of applications.

(5) The MEM is currentiy limited to situations for which the process models must be satisfied exactly. In practice, the process constraints may be satisfied only approximately or process faults may occur during operation or testing. Process noise can be used to account for non-systematic errors. Systematic errors can be modeled either as fixed, but. unknown biases or with explicit models. The use of explicit models permits diagnosis of the fault in addition to reconciliation of the measurements with the process models.

(6) The MEM currentIy does not take measurement biases or the effects of calibration into account. Modification of the MEM algorithm to take these effects into account is desirable.

(7) The existing MEM. algorithm is written in batch form. An incremental algorithm that can be updated following the completion of each process or continuously in time is highly desirable for real-time monitoring applications. The integration of the MEM with the existing data acquisition and monitoring and control system is an area requiring further study.

(8) The current frit addition algorithm performs an exhaustive search over a set of discrete levels of amount of frit to be added. 
Use of multi-objective mathematical optimization techniques may lead to improvement in. the performance of the algorithm.

(9) The current frit addition algorithm assumes that the composition of the frit to be added is known a priori. Joint optimization of frit composition and level may lead to higher waste loading factors. The oWI study is currently reviewing this issue [Hoza, 1993].

(10) Use of a declarative framework for implementation will facilitate the integration of existing code modules in a broader class of problem solving algorithms and results in an extensible architecture that can be readily adapted to a wide range of plant configurations, operational scenarios, and analysis goals (estimation, optimization, simulation). The only currently available commercial inference engine that satisfies the requirements of an epistemologically comprehensive knowledge representation and a sound and complete inference engine is EPIKIT, which makes it an ideal environment for accomplishing the Integration referred: to here. Epistemologically comprehensive refers to the expressiveness of the language and means that $a$ wide variety of concepts may be represented in the language. An inference engine is sound if produces only correct results. An inference engine is complete if it produces every correct result. Code developed in FORTRAN can easily be integrated into the EPIKIT environment by augmenting the FORTRAN code with a declarative description that describes its inputs and outputs and any assumptions made by the code developer that restrict its applicability. 


\subsection{REFERENCES}

Bar, M., Schaffner, J., Seig, W., and M. Zeitz, "Functionality and implementation of a knowledge-based flowsheet-oriented user interface for the dynamic process simulator DIVA," simuIation, August 1993, p. 117-123.

Bastin, G. and J. Iévine, "On state Accessibility in Reaction Systems," IEEE Trans. Automatic Control, 38(5), 733 (1993).

Britt, H.I., and R.H. Leucke, "The Estimation of Parameters in Nonlinear, Implicit Models," Technometrics, 15 (2), 233 (1973).

Bryan, M.F., and Piepel, G.F., strategy for Product Composition Control in the Hanford Waste Vitrification Plant, PHTD-C93-05.01F, Pacific Northwest Laboratory, Richland, Washington, October, 1993.

Elicabe, G., and C. Georgakis, "On-line Estimation of Reaction Rates in Batch Reactors," 1992 American Control Conference, p. 2373-4.

Fassel, V. A., Science, 202, 183 (1978).

Fuller, Wayne A., Measurement Error Models, John Wiley \& Sons, 1987, ISBN 0-471-08186-8.

Hoza, M. Optimal Waste Loading Models for Vitrification of Hanford High-Level Waste, PHTD-C93-03.01M, Pacific Northwest Laboratory, Richland, Washington, 1993.

Hrma, P.R. and Plepel; G.F. Property/Composition Relationships for Hanford Waste Vitrification plant Glasses--Preliminary Results Through CVS-II Phase-2, PHTD-92-03.01/K897, Pacific Northwest Laboratory, Richland, Washington, 1992.

HWVP, Test Plan HWVP-91-1.2.2.03.03B, Rev. 1

Kalman; R.E., "A new approach to linear filtering and prediction problems". Trans. ASME, J. Basic Engng., 82, 35-45 (1960).

Kalman, R.E. and Bucy, R.S., 1961, "New results in linear filtering and prediction theory", Trans. ASME, J. Basic Engng., 83D, 95-108 (1961).

Knepper, J.C., and J.W. Gorman, "statistical Analysis of Constrained Data Sets," AIChE J., $26(2), 260$ (1980).

Kuhn, W.L., Strategy for HWVP Process/Product Model Development, PHTD-C91-05.01B, Pacific Northwest Laboratory, Richland, Washington, October 1992

MacDonald, R. J., and C. S. Howat, "Data Reconciliation and 
Parameter Estimation in Plant Performance Analysis," AIChE J., 34(1), 1 (1988).

McKay, Rick L. and Monica R. Beckette, Holledge Level Detection System Calibration, Draft. 
APPENDIX A: GENERAL DISCUSSION OF THE USE OF CONSTRAINED WEIGHTED IEAST SOUARES ESTIMATION FOR DATA RECONCIIIATION

For the purposes of clarity, the exposition of the application of nonlinear regression to data reconciliation is carried out under two separate cases. In the first case, it is assumed that all quantities for which an estimate is desired are measured. In the second case it is assumed that some of the parameters to be estimated are not measured.

Case 1: All Estimated Quantities Are Measured.

In this case we assume that the measurement vector, $z$, differs from the vector of true values, $I$, only by the addition of zero mean, additive Gaussian (normally distributed) noise, E:

$$
\underline{z}=\underline{\tau}+\underline{\epsilon} .
$$

By Gaussian noise, it: is meant that the distribution function of the noise is normally distributed. The covariance matrix, $R$, of the . measurement noise, $\underline{\epsilon}$, is assumed to be known a priori.

The true values, $I$, are known to obey a set of constraints (e.g.,material balance, efficiency, sum of mole fractions, enthalpy balance) that can be expressed in vector form as:

$$
\underline{\underline{f}}(\underline{\tau})=\underline{0}
$$

The statistical development here follows that of Britt and leucke (1973). For one set of measurements the probability density function for the measured data is:

$$
f(z)=\frac{1}{(2 \pi)^{\frac{n}{2}}|R|^{\frac{1}{2}}} \exp \left[\frac{(z-\tau)^{T} R^{-1}(z-\tau)}{2}\right]
$$

where

$\{R \mid$ is the determinant of $R$.

Maximum likelihood estimation reduces the problem to the following: Minimize: $(\underline{z}-\underline{\tau})^{T} R^{-1}(\underline{z}-\underline{\tau})$

Subject to the constraints: $\underline{\underline{f}}(\underline{\tau})=0$

Some insight into the meaning of the objective function being minimized in equation (A.4) can be obtained by considering the 
special case when there is no covariance among the measured data. In that case, the quantity

reduces to:

$$
(\underline{z}-\underline{\tau})^{\mathrm{T}} \mathrm{R}^{-1}(\underline{z}-\underline{\tau})
$$

$$
\sum_{i=1}^{n} \frac{(z-\tau)^{2}}{\left(\sigma_{1}\right)^{2}}
$$

Thus it can be seen that the statistical "best" adjustment to the data is that which satisfies the constraints while minimizing the sum of squares adjustment to the measured data.

Britt and Leucke (1973) use the method of Lagrange multipliers with a Taylor expansion about the nonlinear constraints to obtain the following iterative algorithm for the determination of the best adjustment to the data. Their iterative algorithm is:

$$
\tau_{1+1}=\tau_{0}+R H_{1}^{T}\left(H_{1} R H_{1}^{T}\right)^{-1}\left[H_{1}\left(\tau_{1}-\tau_{0}\right)-f\left(\tau_{1}\right)\right]
$$

where $H_{f}$ is the $m \times n$ Jacobian matrix resulting from differentiating the $n$ constraint equations $m$ with respect to the m-dimensional measurement vector $I_{i}$, evaluated at $\tau_{i}$.

Equation A.3 is recalculated until the absolute values of the constraint discrepancies are less than some tolerance, that is,

$$
\left|\underline{f}\left(\underline{\tau}_{i+1}\right)\right|<\epsilon_{0}
$$

The variance covariance matrix for $I_{0}$ that is calculated according to the iterative algorithm is given by Knepper and Gorman (1980):

$$
\mathscr{E}\left[\left(\tau_{\theta}-\tau\right)\left(\tau_{a}-\tau\right) \tau\right]=R-R H_{1}^{T}\left(H_{1} R H_{1}^{T}\right)^{-1} H_{1} R
$$

Case 2: Some Estimated Quantities Are Not Measured 
The more general problem is where a number of unmeasured parameters $\theta$ are part of the constraint equations, that is, to find the "best estimates, $\tau_{0}$ and $\theta_{0}$ simultaneously such that $f\left(\tau_{0}, \theta_{e}\right)=0$. For the maximum likelihood, the problem now becomes:

Minimize: $(z-T)^{T} R^{-1}(z-\tau)$

subject to the constraints: $f\left(\tau_{0}, \theta_{0}\right)=0$.

Following the development of Britt and Leucke (1973), the iterative equations are:

$$
\begin{gathered}
\theta_{k+1}=\theta_{k}+\left[F_{\theta}^{T}\left(F_{z} R F_{z}^{T}\right)^{-1} F_{\theta}\right]^{-1} F_{\theta}^{T}\left(F_{z} R F_{z}\right)^{-1} \\
\cdot\left[F_{z}\left(z_{k}-z_{0}\right)-f\left(z_{k}, \theta_{k}\right)\right] \\
\cdot \\
z_{k+1}=z_{0}+R F_{z} T\left(F_{z} R F_{z}{ }^{T}\right)^{-1}\left[F_{z}\left(z_{k}-z_{0}\right)-F_{\theta}\left(\theta_{k+1}-\theta_{k}\right)-f\left(z_{k}, \theta_{k}\right)\right]
\end{gathered}
$$

where $F_{z}$ includes the partial derivatives for the measured variables and $F_{0}$ is an $p \times$ In Jacobian matrix obtained by differentiating $f$

The estimated variance-covariance matrix for the measured
parameters, $z$, is:

$$
\mathscr{E}\left[(z-\tilde{z})(z-\tilde{z})^{T}\right]=R-R F_{z}{ }^{T} Q\left(Q^{-1}-F_{\theta}\left(F_{\theta}^{T} Q F_{\theta}\right)^{-1} F_{\theta}^{T}\right) Q F_{z} R
$$

where

$$
Q=\left(\left(\mathrm{H}_{\mathrm{i}}\right)^{\mathrm{T}} \mathrm{RH}_{\mathrm{i}}\right)^{-1}
$$

The $\mathrm{p} \times \mathrm{p}$ variance-covariance matrix for the unmeasured parameters
is:

$$
\mathscr{E}\left[(\theta-\theta)(\theta-\theta)^{T}\right]=\left(F_{\theta}^{T} Q F_{\theta}\right)^{-1}
$$




\section{APPENDIX B: HWVP MEM ALGORITHM}

In this section the equations for the first application of the MEM, namely, the estimation of SME compositions, given the level, specific gravity, and concentration measurements for the RWCT, SRAT, and SME, as described in section 3.0, are given.

In this case, the measurement vector for the HWVP MEM algorithm is a vector of length 56 defined as follows:

The first 8 components represent the outputs of the Holledge level detectors in both of the tank states \{empty, full\}:

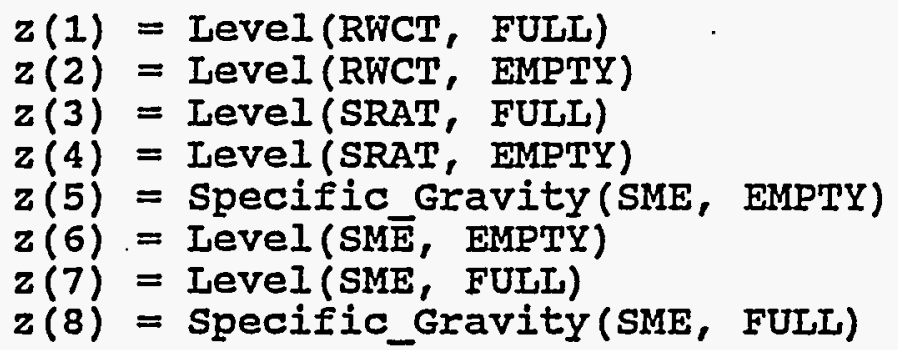

The next $40^{\prime}$ components represent the ICP concentrations for each of the 10 species measure in four different tank states:

$z(9), \ldots, z(18)=$ concentration(RWCT, FULL, Sio $), \ldots$, concentration (RWCT, FULL, OTHER);

$z(19), \ldots, z(28)=$ concentration(SRAT, FULI, $\mathrm{SiO}_{2}$ ), ..., concentration (SRAT, FULL, OTHER);

$z(29), \ldots, z(38)=$ concentration(SME, EMPTY, SiO $\left.\mathrm{S}_{2}\right), \ldots$, concentration (SME, EMPTY, OTHER);

$z(39), \ldots, z(48)=$ concentration(SME, FULI, $\mathrm{SiO}_{2}$ ), ..., concentration (SME, FULL, OTHER);

The complete set of 10 species for which concentrations are defined is:

$\left\{\mathrm{SiO}_{2}, \mathrm{~B}_{2} \mathrm{O}_{3}, \mathrm{NaO}_{2}, \mathrm{Ii}_{2} \mathrm{O}, \mathrm{CaO}, \mathrm{MgO}, \mathrm{Fe}_{2} \mathrm{O}_{3}, \mathrm{AI}_{2} \mathrm{O}_{3}, \mathrm{ZrO}_{2}\right.$, OTHER $\}$

The next 4 elements of the measurement vector contain the masses of the ICP samples under the same 4 tank states:

$\mathbf{z}(49)=1$ iquid mass (RWCT, FULI),
$\mathbf{z}(50)=1$ iquidmass (SRAT, FULL),
$\mathbf{z}(51)=1$ iquidmass (SME, EMPTY),
$\mathbf{z}(52)=1$ iquid_mass (SME, FULL).

The final 4 elements of the measurement vector contain the masses of the contents of the tank in each of the same 4 tank states:

$z(53)$ = sample_weight (RWCT, FULL),

$z(54)=$ sample_weight (SRAT, FULI), 
$z(55)$ = sample_weight (SME, EMPTY),

$z(56)=$ sample_weight (SME, FULI).

The unmeasured, but estimable variables in this case are the levels in the Slurry Mix Evaporator Condensate Tank (SMECT) before and after evaporation form the SME. It is assumed that level changes in the SMECT are due only to evaporation from the SME.

There are a total of 15 constraints. The first five constraints are defined as follows:

(1) mass transfer balance for the total mass

(2) ICP sample mass species balance for \{SRAT, FULI\}

(3) ICP sample mass species balance for \{RWCT, FULI\}

(4) ICP sample mass species balance for \{SME, EMPTY\}

(5) ICP sample mass species balance for \{SME, FULL\}

Constraints 6-15 represent mass transfer balances for each of the 10 species in the slurry.

With these definitions, and defining the scalar variable $\theta$ by:

$$
\theta=\text { Level (SMECT, FULL) - Level (SMECT, EMPTY), }
$$

the constraints can be written in matrix form as:

$$
\mathrm{Cz}+\theta\left(-\mathrm{C}_{\mathrm{L}}(\mathrm{SMECT}), 0, \ldots, 0\right)^{\mathrm{T}}=0
$$

where $c$ is a matrix of coefficients, and $c_{i j}$ specifies the coefficient of the jth measurement in the ith constraint.

The c matrix has the from shown below:

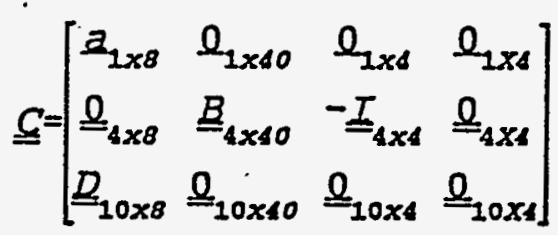

where $a$ is the 8-vector defined by:

The coefficients in the a vector are defined by:

$$
C_{L}(\text { tank })=A\left(\text { tank }_{\mathrm{i}}\right) * \rho\left(\text { tank }_{\mathrm{i}} \text {, tank-state } \mathrm{t}_{\mathrm{j}}\right)
$$

$A\left(\operatorname{tank} k_{i}\right)$ is the cross-sectional area of the ith tank,

$\rho\left(\operatorname{tank}_{1}\right.$, tank-state $\left._{j}\right)$ is'the density of the slurry in the ith tank, 


$$
a^{T}=\left(\begin{array}{c}
C_{L}(S F H T) \\
-C_{L}(S F H T) \\
C_{L}(S R A T) \\
-C_{L}(S R A T) \\
-C_{S G}(S M E, E M P T Y) \\
-C_{L}(S M E, E M P T Y) \\
C_{L}(S M E, F U L L) \\
C_{S G}(S M E, F U L L)
\end{array}\right)
$$

when the tank is in state $j$.

For the RWCT and the SRAT, where no mixing or heating occurs, it is assumed that

$$
\rho\left(\operatorname{tank}_{i}, \text { EMPTY }\right)=\rho\left(\operatorname{tank}_{i}, \text { FULI }\right)=\rho\left(\tan k_{i}\right),
$$

Furthermore, for the SME

$\mathrm{C}_{\text {So }}$ (SME, TANK-STATE $)=A(S M E) *\left(h_{0}\right.$ (SME) $/ / h_{m}$ (SME))* $\rho$ (SME, TANK-STATE $)$

where

$h_{m}$ is the distance between the two density dip tubes of the Holledge level detector,

$h_{0}$ is the height of the lowest dip tube above the floor, and $\rho$ (SME, TANK-STATE $)_{j}$ is the oxides per solution of the SME in state $j$, where $j$ is either EMPTY, OR FULI.

The $B$ matrix is defined by

$$
B_{4 \times 10}=\left[\begin{array}{llll}
I_{1 \times 10} & l_{1 \times 10} & l_{1 \times 10} & l_{1 \times 10} \\
l_{1 \times 10} & I_{1 \times 10} & l_{1 \times 10} & l_{1 \times 10} \\
l_{1 \times 10} & l_{1 \times 10} & I_{1 \times 10} & l_{1 \times 10} \\
O_{1 \times 10} & l_{1 \times 10} & l_{1 \times 10} & l_{1 \times 10}
\end{array}\right]
$$

where 1 is a vector consisting of all ones, i.e., $\underline{1}_{1 \times 10}=(1,1,1,1,1,1,1,1,1,1)$.

The coefficients of the $D$ matrix are defined as follows: 


$$
d_{11}=\frac{C_{L}(S F H T) * \text { concentration }(S F H T, F U L L, \text { SPECIES })}{\text { sample-weight }(S F H T, F U L L)}
$$

$$
d_{12}=-d_{11}
$$

$$
a_{13}=\frac{C_{L}(S R A T) * \text { concentration }\left(\text { SRA, FULL, SPECIES } S_{1}\right)}{\text { sample-weight }(S R A T, F U L L)}
$$

$$
\begin{aligned}
& \mathrm{d}_{14}=-\mathrm{d}_{13}, \\
& d_{15}(S M E, E M P T Y)=\frac{C_{S G}(S M E, E M P T Y) * \text { concentration }(S M E, E M P T Y, \text { SPECIES })}{\text { sample-weight }(S M E, \text { EMPTY })}
\end{aligned}
$$

$d_{i B}=-a_{i s}(S M E, F U L L)$

$d_{16}(S M E, E M P T Y)=\frac{C_{L}(S M E, E M P T Y) * \text { concentration }\left(S M E, E M P T Y, \text { SPECIES } S_{1}\right)}{\text { sample-weight }(S M E, E M P T Y)}$

and

$a_{i 7}=-d_{16}$ (SHE, FULL)

34 


\section{APPENDIX C: FRIT ADDITION ALGORITHM}

The composition in the SME is controlled by adding an amount of fresh frit to the combined raw waste and recycled frit in the SME: In order to maximize the throughput of raw waste, it is desirable to add the smallest amount of frit that will result in an acceptable and processable feed composition. The composition of the feed prior to the addition of frit is determined by the MEM algorithm. The relationship between the feed composition and glass properties is assumed to obey a linear relationship in the mass fractions of the oxides in the slurry. Thus for the ith glass property, $i=1, \ldots, k$, where $k$ is the number of waste glass properties considered by the frit addition algorithm:

$$
\hat{y}_{1}=C_{1} \beta_{11}+C_{2} \beta_{12}+\ldots+C_{n} \beta_{i_{n}}=C^{T} \beta_{1}
$$

where $y_{1}$ is the ith waste glass property, $c_{j}$ is the $j$ th oxide mass fraction, $j=i, \ldots, N_{o x}$ and $\beta_{i j}$ is the regression coefficient expressing the relationship between the ith waste glass property and the jth oxide mass fraction. The covariance matrix of the regression coefficients is assumed known. The development of property models relating feed composition to melt and glass properties, is one of the objectives of the composition variability study. The CVS is described in detail by Hrma and piepel (1992).

An estimate of the mass in the SME before the frit is added can be expressed as:

$$
\hat{M}_{S U M B}=\frac{A_{R}}{g}\left(\frac{h_{0}^{\prime}}{h_{1}} \hat{P}_{1 S}+\hat{P}_{2 S}\right)
$$

where the estimates $P_{i s,} i=1,2$, of the pressure differences in the SME prior to frit addition are obtained from the MEM algorithm.

Assuming that the mass of frit to be added to the SME is given by $\mathfrak{m}_{1}$, the composition of the SME after adding frit can be obtained as:

$$
C\left(S M E, t_{2}\right)=\frac{m_{1}}{\left(m_{1}+\hat{M}_{S M E}\right)} \partial^{T}(E I i t)+\left(1-\frac{m_{1}}{\left(m_{1}+\hat{M}_{S K B}\right)}\right) \hat{C}\left(S M E, t_{1}\right)
$$

where $c$ (frit) is the vector of mass fractions of the frit, and $c\left(S M E, t_{i}\right)$ is the vector of mass fractions of the SME at times, $t_{1}$, prior to frit addition, and $t_{2}$, after frit addition. 
Substituting equation C.3 into equation C.1, we obtain

$$
\begin{gathered}
\rho\left(m_{1}, t_{2}\right)=\frac{m_{1}}{\left(m_{1}+\hat{M}_{S M B}\right)} e^{T}\left(\text { fIit) } \beta_{1}+\right. \\
+\left(1-\frac{m_{1}}{\left(m_{1}+\hat{M}_{S M E}\right)}\right) e^{T}\left(S M E, t_{1}\right) \beta_{1}
\end{gathered}
$$

The variance of each waste glass property can be estimated approximately as:

$$
\begin{aligned}
& \operatorname{var}\left(\rho_{1}\right)=g_{1}^{i} \operatorname{diag}\left(\Sigma_{1}, \Sigma_{2}, \sigma^{2}, V_{1}\right) g_{1}, \\
& \text { where } \\
& \Sigma_{1}=\operatorname{Var}(C(\text { frit })), \\
& \Sigma_{2}=\operatorname{Var}\left(\left[\begin{array}{c}
\hat{P}_{1 S} \\
\hat{P}_{2 S} \\
C\left(S M E, t_{1}\right)
\end{array}\right]\right), \\
& \sigma^{2}=\operatorname{var}\left(m_{1}\right), \\
& \operatorname{Vin}_{1}=\operatorname{Var}\left(\beta_{1}\right) .
\end{aligned}
$$

$g_{1}$ is the gradient of $y_{1}$ with respect to the vector $p_{1}$, where

$$
p_{1}=\left(\lambda(f r i t), \hat{P}_{2 s}, \hat{P}_{2 S}, \hat{C}\left(S M E, t_{2}\right), m_{1}, \hat{\beta}_{1}\right)
$$

The vector of mass fractions of the frit, the vector of mass fraction estimates from the SME, and the vector of regression coefficients for the $i$ th waste glass property have dimension equal to the number of oxides in the siurry, $N_{0 x}$. The pressure measurements and the mass of the frit to be added to the SME are scalars. The dimension of the vector $p$ is therefore, $3\left(N_{o x}+1\right)$.
Hence,

$$
\begin{gathered}
: \quad \dot{g}_{11}=\frac{m_{1}}{\left(m_{1}+\hat{M}_{S M B}\right)} \beta_{1} \\
g_{12}=\frac{m_{1}\left(\frac{A_{R}}{g} \frac{h_{0}}{h_{1}}\right)}{\left(m_{1}+\hat{M}_{S M B B}\right)^{2}}\left(C\left(S M E, t_{2}\right)-\left(c(\text { fIit) })^{\top} \beta_{1}\right.\right.
\end{gathered}
$$




$$
\begin{aligned}
& \text { - } g_{13}=\frac{m_{1}\left(\frac{A_{R}}{g}\right)}{\left(m_{1}+\hat{M}_{\text {SMIS }}\right)^{2}}\left(C\left(\text { SME }, t_{1}\right)-a(f r i t)\right)^{T} \beta_{1} \\
& g_{14}=\left[1-\frac{m_{1}}{\left(m_{1}+\hat{M}_{S M B R}\right)}\right] \beta_{1} \\
& g_{15}=\frac{\hat{M}_{S M E}}{\left(m_{1}+\hat{M}_{S M E}\right)^{2}}\left(\alpha \cdot(f I i t)-c\left(S M E, t_{1}\right)\right)^{x} \beta_{1} \\
& g_{6}=\frac{m_{1}}{\left(m_{1}+\hat{M}_{S L I P}\right)} a(f I i . t)+\left(1-\frac{m_{1}}{\left(m_{1}+\hat{M}_{S T B B}\right)}\right) a\left(S M E, t_{1}\right)
\end{aligned}
$$

Equations (C-7) through (C-12) are the individual components of the gradient vector, which has the overall form:

$$
g_{i}=\left(g_{i 1}, g_{i 2}, g_{13}, g_{i 4}, g_{i 3}, g_{6}\right)
$$

It is assumed that for each glass property, upper and lower bounds on acceptable values of that property have been specified. Given limits of acceptable glass characteristics, $I_{1}$, and $U_{i}$, for the $i$ th glass property, the frit level to be added is accepted if the lower limit, $I_{i}$ is less than the mean minus two standard deviations and the upper limit, $U_{i}$, is greater than the mean plus two standard deviations. The frit addition algorithm iterates over the range of possible frit levels (the maximum frit to be added is limited by the capacity of the tank) in 1000 increments of frit addition level, which translates to frit masses of about 10 to 15 pounds per increment. At each level of frit addition, and for each glass property, the best estimate and variance of that property for a given composition is calculated using the above expressions. The minimum acceptable value of added frit for that particular property. is stored in a temporary array. After all six properties have been evaluated in this manner, the actual frit to be added is taken as the maximum of the six minimums obtained for each property. The value of frit added is therefore the maximum value that guarantees that the mean of every glass characteristic is no closer than 2 standard deviations to its limiting values. The use of standard deviation. as a basis for comparing the estimated values to the property acceptance limits is an approximation used to test the 
algorithm. If the distribution function associated with the property estimate and its varlance are known, then the test can be specified directiy in terms of the probability that the level of frit added will result in an acceptable and processable glass.

1 


\section{APPENDIX D: SUMMARY OF SIPT TEST METHODOLOGY}

A general description of the Feed Preparation Test System in terms of equipment, processes and tests to be performed is presented in Section 3.0. This appendix gives further details on the operational characteristics of the Test Plan.

\section{D.1 BLURRY RECEIPT AND ADJUBTMENT TANR (BRAT) BIMULANT PROCEBSING}

\section{D.1.1. Bimulant preparation}

The operating performance of much of the feed preparation equipment as well as the ability of the test vessel to maintain homogeneity is dependent upon the volume of feed in the tank. Therefore, testing is performed at two volumes:

(1) the nominal operating volume (approximately 7800 gallons), and

(2) nine inches above the top of the coils (approximately 5600 gallons).

In the sequel, the two volumes mentioned above are referred to as the high and low levels, respectively. Thus, the terms high and low levels refer to volume of slurry and not to the level of radioactivity.

\section{D.1.1.1 Low Level Tests}

Initially 4000 gallons of HWVP feed simulant is prepared in Tank HB-13. A sample is then taken from $H B-13$ and analyzed for material balance purposes. After the simulant is transferred to the full scale test vessel, it is diluted to approximately 5600 gallons.

(1) Prepare simulated waste to approximately 45 grams of waste oxides per liter of melt feed in Tank $\mathrm{HB}-13$

(2) Sample $\mathrm{HB}-13$ for complete simulant characterization.

(3) Transfer slurry from Tank HB-13. to tank HB-15

(4) Dilute the concentration to 31 grams of waste oxide per liter

(5) Perform Homogeneity Tests

(6) Perform Pumping Tests

(7) Perform Evaporator/Condenser Tests

\section{D.1.1.2 High Level Tests}

To bring the total volume of dilute slurry in the full-scale test vessel to 7800 gallons, an additional 2200 gallons of HWVP feed simulant is prepared in Tank $\mathrm{HB}-13$, sampled, and then transferred to the full scale test vessel.

(1) Prepare 2200 gallons of dilute (31 grams/iiter) of simulated waste in Tank $\mathrm{HB}-13$

(2) Sample $\mathrm{HB}-13$ for complete simulant characterization.

(3) Transfer slurry from Tank $\mathrm{HB}-13$ to tank $\mathrm{HB}-15$ 
(4) Perform Homogeneity Tests

(5) Perform pumping Tests

(6) Perform Evaporator/Condenser Tests -

\section{D.1.2 Feed Concentration Tests (Heating, Boiling, Cooling)}

The feed concentration process test will demonstrate the concentration of HWVP simulated feed in the SRAT from 31 grams waste oxide per liter of melter feed to approximately 140 grams waste oxide per liter of melter feed. Following equipment characterization with the dilute feed simulant, the contents of tank $\mathrm{HB}-15$ will be concentrated by boiling the slurry for approximately 45 hours, condensing approximately 10 gpm condensate, and adding 27,000 gallons of dilute HWV feed simulant at a corresponding rate. The 27,000 gallons of feed slurry will be prepared as 6 batches of 4,000 gallons and one batch of 3,000 gallons in Tank $\mathrm{HB}-13$. During each phase of boiling the condensate is directed to $\mathrm{HB}-14$, and condensate and aerosol samples are taken.

(1) The contents of the full-scale vessel are first evaporated from 7800 gallons to 5600 gallons by boiling at the maximum steam flow rate.

(2)-(7) While boiling at one of three steam flow rates, 4000 gallons of dilute feed simulant from $\mathrm{HB}-13$ is added at a rate approximately equal to the generation rate of the condensate (the final tank volume increases by about 3000 gallons). Two cycles of concentration are performed at each of three steam flow rates.

(8) While boiling at medium steam flow rate, 3200 gallons of dilute feed simulant from $\mathrm{HB}-13$ is added at a rate approximately equal to the generation rate of the condensate (the final tank volume is about 7700 gallons).

(9) After concentration has been completed, 2100 gallons of concentrated feed are transferred from tank $\mathrm{HB}-15$ to $\mathrm{HB}-13$.

\section{D.1.2.I LOW Ievel Concentrated Feed Tests}

(10) Perform Homogeneity Tests

(11) Perform Evaporator/Condenser Tests

\section{D.1.2.2 High Level Concentrated Feed Tests}

(12) Tank HB-15 is returned to full level by pumping 2100 gallons of concentrated simulant from Tank HB-13 to Tank HB-15.

(13) Perform Homogeneity Test's

(14) Perform pumping Tests

(15) Perform Evaporator/Condenser Tests

\section{D.1.3 Formio Acid and Reaction Tests}

Formic acid facilitates the oxidation-reduction reaction and inhibits foaming within the melter and changes the slurry rheology. 
Following concentration and slurry testing, the slurry temperature is adjusted to $95^{\circ} \mathrm{C}$ and 90 wto formic acid is added to the slurry at a controlled rate. Following the addition of formic acid, the formated slurry is digested. Finally the slurry batch is cooled to $50^{\circ} \mathrm{C}$ and sampled to verify the concentration and composition. 300 gallons of formic acid are added at $2 \mathrm{gpm}$ and digested for 4 hours.

The nature and magnitude of process effluent losses associated with feed preparation operations is assessed by examining secondary waste stream compositions. On a mass basis, gaseous losses dominate feed preparation effluent emission rates. The temporal emission rate behavior of several gases is continuously monitored with specific gas analyzers. Physical entrainment of feed matter during feed preparation is the only significant loss mechanism responsible for off-gas aerosol. Elemental. constituents of the process generated aerosols are determined by conventional batch filtration methods in conjunction with off-line laboratory analysis. To characterize condensate losses, the composition of the process condenser waste stream is characterized using batch sampling techniques and analyzed during each process operation.

Homogeneity Tests and Pumping Tests are performed for the Formated HWVP simulant.

\section{D.2. SLURRY MIX EVAPORATOR (BME) SIMULANT PROCESBING}

In the SME, recycle waste and process frit are added to the formated slurry. The total oxide concentration is controlled by the amount of. frit added to the formated slurry and the volume of feed in the test vessel. Following slurry adjustment, the feed is cooled and sampled in preparation to be sent to the Melter Feed Tank (MFT):

\section{D.2.1. Recycle Haste Adaition (two batches)}

Recycle addition occurs in two batches to the prototypic SME. As the recycle waste batch is prepared in tank $\mathrm{HB}-13$, the contents of Tank HB-15 are concentrated to approximately 5700 gallons in preparation for recycle addition. The recycle stream is then transferred to tank HB-15 at approximately $60 \mathrm{gpm}$.

(1) Adjust the volume of formated slurry to 5700 gallons by concentration or water dilution

(2) (a) Prepare two batches ( 4200 gallons) of recycle waste slurry ( 30 grams of oxide per liter of recycle oxide) in Tank $\mathrm{HB}-13$.

(b) Sample $\mathrm{HB}-13$ for complete simulant characterization.

(3) Heat tank $\mathrm{HB}-15$ to boiling.

(4) (a) Calibrate effiuent analyzers as necessary

(b) initial instrumental off-gas analysis

(c) begin filter collection of process generated aerosols

(5) Transfer. first batch (2100 gallons) of recycle slurry from tank 
HB-13 to tank $\mathrm{HB}-15$

(6) (a) Concentrate feed slurry to 5700 gallons

(b) Determine heating and boiling heat transfer coefficients

by heating and concentrating tank $\mathrm{HB}-15$ contents.

(c) evaporate at maximum capacity

(d) collect condensate in tank $\mathrm{HB}-14$

(e) sample condensate

(f) collect off-gas filter sample

(7) Transfer second batch (2100 gallons) of recycle slurry from tank $\mathrm{HB}-13$ to tank $\mathrm{HB}-15$

(8) $\mathrm{CoOl}, \mathrm{HB}-15$ to $50^{\circ} \mathrm{C}$.

\section{D.2.2: Process Frit Addition (two batches)}

The process frit addition also occurs in two batches to the SME. The frit slurry is prepared in $\mathrm{HB}-13$ as a 2900 gallon slurry. It is transferred at $60 \mathrm{gpm}$ in two batches of 1450 galions each following concentration of the test vessel contents.

(1) (a) Prepare two batches (2900 gallons) of process frit slurry in Tank HB-13.

(b) Sample $\mathrm{HB}-13$ for complete simulant characterization.

(2) (a) Calibrate effluent analyzers as necessary

(b) initial instrumental off-gas analysis

(c) begin filter collection of process generated aerosols

(3) (a) Concentrate feed slurry to 5700 galions

(b) Determine heating and boiling heat transfer coefficients

by heating and concentrating tank $\mathrm{HB}-15$ contents.

(c) evaporate at maximum capacity

(d) collect condensate in tank $\mathrm{HB}-14$

(e) sample condensate

(f) collect off-gas filter sample.

(4) (a) Transfer 2200 gallons of process frit slurry from tank HB13 to tank $\mathrm{HB}-15$ at 60 gallons per minute and flush lines.

(b) Maintain tank. $\mathrm{HB}-15$ at full heating and reflux condensate during process frit addition.

(5) Repeat step (3)

(6) Perform evaporator/condenser testing

(7) Repeat step (4) with remaining process frit slurry

(8) Add formic acid and reflux condensate

(9) (a) Digest contents of tank $\mathrm{HB}-15$ at $101^{\circ} \mathrm{C}$ for $2-4$ hours.

(b) Determine boiling heat transfer coefficient.

(c) Collect condensate in tank HB-14.

(10) CoOI HB-15 to $50^{\circ} \mathrm{C}$.

(11) Adjust the concentration of the melter feed slurry to the appropriate weight percent total solids, weight percent total oxides and density by concentration or dilution.

\section{D.3 MeIter Feed Tank (MFT) Bimulant Processing}

Beyond the scope of this study 


\section{APPENDIX E: THE BASIC KAIMAN FILTER EOUATIONS}

optimal state estimation techniques have been developed to provide acceptable estimates of the state variables in spite of the fact that some of these states may not be directly measurable and/or may be subject to random measurement error and process disturbances. These techniques require the definition of a measure of the state estimation error, a knowledge of measurement error statistics, dynamic system models and system disturbance statistics, and

algorithms for using this information to compute minimum-error state estimates. Measurement errors (measurement noise), and process disturbances and modelling inaccuracies (process noise) are treated as stochastic processes in this framework. One of the most popular and powerful estimation techniques, developed in the 1960s, is Kalman filtering (Kalman, 1960; Kalman and Bucy, 1961). In this approach the process dynamics are given in terms of a stochastic process described by a vector stochastic difference equation and the measurement equations are described in terms of an algebraic transformation of the state vector perturbed by noise.

The process dynamic model has the general form:

$$
x\left(t_{k+1}\right)=g\left(x\left(t_{k}\right), \underline{n}_{p}\left(t_{k}\right)\right)
$$

where:

$\underline{x}\left(t_{k}\right)$ is the $n$ dimensional system state, $\underline{g}(\cdot, \cdot)$ is a known n-dimensional state transition function, and $\underline{n}_{p}$ is the $n$-dimensional process noise vector.

An important special case of equation $E-1$ occurs when $n_{p}$ is additive, zero-mean, white, gaussian noise. In that case, equation E-1 can be written as:

$$
x\left(t_{k+1}\right)=g\left(x\left(t_{k}\right)\right)+\underline{n}_{p}\left(t_{k}\right)
$$

where

$$
E\left\{w\left(t_{k}\right)\right\}=0, \quad \text { for aII } t_{k}
$$

The covariance matrix of the process noise vector is given by: 


$$
\operatorname{cov}\left[\underline{n}_{p}\left(t_{y}\right) ; \underline{n}_{p}\left(t_{k}\right)\right]=E\left[\underline{n}_{p}\left(t_{y}\right) \underline{n}_{p}\left(t_{k}\right)\right\}=\delta\left(t_{j}, t_{k}\right) \underline{R}_{p}\left(t_{k}\right)
$$

where $\delta(\cdot, \cdot)$ is the Dirac delta function, and $\underline{R}_{p}\left(t_{k}\right)$ is an nxn symmetric positive definite matrix.

If in addition $g\left(x\left(t_{k}\right)\right)$ is linear, then equation $E-4$ may be further simplified to:

$$
x\left(t_{k+1}\right)=G\left(t_{k}\right) z\left(t_{k}\right)+\underline{n}_{\Omega}\left(t_{k}\right)
$$

where $G\left(t_{k}\right)$ is the $n \times n$ state transition matrix.

The measurement model has the general form: .

$$
x\left(t_{k}\right)=h\left(x\left(t_{k}\right), \underline{n}_{m}\left(t_{k}\right)\right)
$$

where:

$Y\left(t_{k}\right)$ is the $m$-dimensional measurement vector, $\underline{h}(\cdot, \cdot)$ is the m-dimensional measurement transformation function, and

$n_{m}$ is the m-dimensional measurement noise vector.

An important special case occurs when $\underline{h}(\cdot, \cdot)$ is linear and $\underline{n}_{m}$ is additive, zero-mean, white, Gaussian noise. In that case, equation E-6 can be written as.

$$
\Psi\left(t_{k}\right)=H\left(t_{k}\right) x\left(t_{k}\right)+\underline{n}_{m}\left(t_{k}\right)
$$

where

$$
E\left\{\underline{n}_{m}\left(t_{k}\right)\right\}=0, \text { for all } t
$$

The covariance matrix of the measurement noise vector is given by:

$$
\operatorname{cov}\left[\underline{n}_{m}\left(t_{f}\right): \underline{n}_{m}\left(t_{k}\right)\right]=E\left\{\underline{n}_{m}\left(t_{f}\right) \underline{n}_{m}\left(t_{k}\right)\right\}=\delta\left(t_{f}, t_{k}\right) \underline{R}_{m}\left(t_{k}\right)
$$

where $R_{m}\left(t_{k}\right)$ is an mxm symmetric positive definite matrix.

When both process and measurement equations are linear and process noise and measurement noises are both additive, zero mean, Gaussian white noises, and are uncorrelated with each other, and the noise covariance matrices are known a priori, then the algorithm which obtains the optimal state estimate under the minimum mean squared state estimation error criterion is the Kalman filter. Several 
extensions to the basic Kalman filtering algorithm are available when some or all of the assumptions mentioned above are not satisfied in practice. Several commonly used methods for dealing with nonlinearity (e.g., extended kalman filter) are based on local linearization of the process model around the current filter estimates. Process and measurement noise statistics can be estimated on-line. The same basic approach can be used when some of the parameters of the process are unknown by augmenting the state vector with those parameters whose values are unknown.

The Kalman filter algorithm consists of two stages,

(I) estimate propagation, in which the process dynamics and the process noise statistics are used to propagate the state estimate at the current time to obtain a predicted state estimate at some time in the future, and

(2) measurement updating, in which the predicted state estimate at the time of measurement is combined with the measured value to provide an updated filtered measurement at the measurement time. The relative strength of the predicted state covariance and the measurement covariance are used to compute the weight, or Kalman filter gain, which balances contributions to the updated state estimate from the predicted state estimate and the measurement. If the ratio of the predicted state estimation error to the measurement error is small, then the filter assigns greater weight to the predicted state estimate. Conversely, if this ratio is large, then the measured value is favored in the computation of the updated state estimate.

The explicit equations for the Kalman filter are as follows:

(1) State Estimate Propagation.

$$
8\left(t_{k+1} i t_{k}\right)=f\left(8\left(t_{k} ; t_{k}\right)\right)
$$

(2) Estimate Covariance Propagation

$$
E\left(t_{k+1} ; t_{k}\right)=\underline{F}_{x}\left(z\left(t_{k} ; t_{k}\right)\right) P\left(t_{k} ; t_{k}\right) \underline{E}_{x}\left(\&\left(t_{k} ; t_{k}\right)\right)+\underline{R}_{p}\left(t_{k}\right)
$$

(3) Filter Gain Computation

$$
\begin{gathered}
E\left(t_{k+1}\right)=P\left(t_{k+1} ; t_{k}\right) \underline{H}_{x}^{T}\left(\&\left(t_{k+1}\right)\right) \cdot \\
{\left[\underline { H } _ { x } ^ { T } \left(\&\left(t_{k+1}\right) E\left(t_{k+1} ! t_{k}\right) \underline{H}_{x}\left(\&\left(t_{k+1} i t_{k}\right)+\underline{R}_{m}\left(t_{k+1}\right)\right]^{-1}\right.\right.}
\end{gathered}
$$

(4) State Estimate Update

$$
\begin{gathered}
8\left(t_{k+1} i t_{k+1}\right)=8\left(t_{k+1} \mid t_{k}\right)+K(k+1) . \\
\cdot\left[x(k+1)-\underline{H}_{x}\left(8\left(t_{k+1} ; t_{k}\right)\right) \&\left(t_{k+1} ; t_{k}\right)\right]
\end{gathered}
$$

(5) Covariance Estimate Update 


$$
P\left(t_{k+1} \mid t_{k+1}\right)=\left[I-K(k+1) \underline{H_{x}}\left(8\left(t_{k+1} \mid t_{k}\right)\right] P\left(t_{k+1} \mid t_{k}\right)\right.
$$

In the equations above the notation $\underline{x}\left(t_{i} \mid t_{j}\right)$ is use to denote that the conditional mean of the state at time, $t_{1}$, is conditioned on the set of all measurements received prior. to time, $t_{j}$, that is

$$
\dot{s}\left(t_{f} \mid t_{k}\right)=E\left[x\left(t_{f}\right) \mid Y\left(t_{k}\right)\right]
$$

and.

$$
P\left(t_{y} ; t_{k}\right)=\operatorname{cov}\left[x\left(t_{y}\right) ; x\left(t_{j}\right): Y\left(t_{k}\right)\right]
$$

where $Y(t)$ is the set of all past measurements; i.e.,

$$
Y\left(t_{k}\right)=\left\{y(0) ; y(1), \ldots, y\left(t_{k}\right)\right\} \text {. }
$$

The equations shown are for the extended Kalman filter, which addresses the nonlinear. filtering problem given by a process description of the form of equation $\mathrm{E}-2$ and a measurement model that specializes equation $E-6$ in analogous way by assuming additive white, gaussian noise, but retains a nonlinear relationship between the state and the state transition function. The extended Kalman filter is based on linearization of the state equations at each time step and the use of linear estimation theory (the Kalman filter).

$\mathrm{H}_{x}\left(\mathrm{x}\left(t_{k}+1 \mid t_{k}\right)\right)$ is the gradient of the measurement matrix with respect to the state vector evaluated at the current predicted state estimate and $F_{x}\left(x\left(t_{k} \mid t_{k}\right)\right)$ is the gradient of the state transition matrix with respect to. the state vector evaluated at the filtered state estimate.

We can make the following comparisons between the nonlinear regression algorithm and the Kalman filtering algorithm.

(1) The nonilnear regression algorithm iterates over successive approximations to the best estimate at the same instant of time. A starting value is chosen and iteratively updated until the convergence criterion is satisfied. Each estimate represents a more precise estimate of the state at the same instant of time. After the algorithm has converged, the covariance of the estimate is computed.

(2) The Kalman filter 'iterates over successive instants of time. The best estimate at the current time is projected and combined with the measured value at the next instant of time to produce the best estimate of the state at the next instant of time.

(3) The constraints used in the nonlinear regression algorithm refer to relationships between the variables at the same instant of time (i.e., the constraints are algebraic). To refer to 
measurements of the same variable at different estimates of time, a new state variable at each time must be defined.

(4) In the Kalman filter the constraints represent relations that hold between variables at adjacent instants of time (i.e., the constraints are differential equations). State variables and their estimates are considered as time series.

(5) By setting the process noise in the Kalman filtering equations to zero and letting the predicted covariance matrix in the Kalman filter equations be equal to the measurement covariance matrix, it can be seen that the form of the covariance update equation for the nonlinear regression method in case 1 and the Kalman filter have the same form. Furthermore, under the additional substitution that the measurement covariance matrix goes to zero, the Kalman filter gain reduces to the gain term in the state update equation for the nonlinear regression method in case 1 .

The solution for the strictly linear case represented by equations $\mathrm{E}-5$ and $\mathrm{E}-7$ has a similar form to the above except that the gradient matrices are replaced by the corresponding state transition matrices. 


\section{APPENDIX F: PROCESS CONSTRAINT MODELS}

The process constraint models specify the relationships between the plant component and process state variables that must be satisfied in any self-consistent solution for the global behavior of the plant. In the specification of the transfer of materials between tanks, these constraints consist of two types:

(1) Mass balance for the components of a mixture, and

(2) Specification of the total mass change and any changes in the relative concentrations of the components that occur.as the result of the tank transfer process.

Type 1 constraints are algebraic in nature and must hold for every contained liquid at all times in the plant operational scenario. If we define the mass of species $i$ in tank $j$ at time $t$ as mass (species, tank $_{j}, t$ ) and the total mass of the liquid in tank as mass (contained-liquid, tank, $t$ ), then the mass balance constraints can be written as:

$$
\begin{gathered}
\operatorname{mass}\left(\text { contained-1iquid, } \tan _{y}, t\right)= \\
=\sum_{j=1}^{N_{s}} \operatorname{mass}\left(\text { species }_{f}, \tan _{j}, t\right)
\end{gathered}
$$

where $\mathrm{N}_{3}$ is the total number of chemical species in the liquid contained in the tank. Equation F.I must be satisfied for every tank or sample in the scenario at every instant of time $t$. In the case of a single transfer between two tanks, and assuming that equilibrium states before and after transfer are of interest, there are four instantiations of equation F.1 that define the species mass balance of the contained liquid in the source tank and in the receiving tank before and after transfer.

Type 2 constraints constitute the behavioral models of the process under study. In the case of the transfer of liquid from one tank to another, there are two subtypes of type 2 constraints specifying the behavioral model. The first subtype of behavioral constraint specifies the relation between the total masses in the tanks and the second subtype specifies the relationship between the relative concentrations before and after transfer. These constraints can be - expressed either in algebraic or differential form. The algebraic form is used if the analyst is only interested in equilibrium masses at some instants of time prior to transfer, $t_{p t,}$ and after transfer, $t_{a t}$. The differential form is used if the analyst is interested in monitoring the total mass and species concentrations continuously. The algebraic form of the behavioral model of an ideal tank transfer, in which no change in the relative concentrations among the constituent species occurs can therefore 
be expressed as follows:

mass (contained-liquid, tank ${ }_{s}, t_{p t}$ )-mass (contained-Iiquid, tank $k_{s}, t_{a t}$ ) mass (contained-1iquid, $\left.\operatorname{tank}_{R}, t_{a t}\right)-$ mass (contained-Iiquid, $\operatorname{tank}_{R}, t_{p t}$ )

and

$$
\begin{aligned}
& \operatorname{mass}\left(\operatorname{species}_{1}, \operatorname{tank}_{s}, t_{p t}\right)-\operatorname{mass}\left(\operatorname{species}_{1}, \operatorname{tank}_{s}, t_{a t}\right) \\
& \operatorname{mass}\left(\operatorname{species}_{1}, \operatorname{tank}_{R}, t_{a t}\right) \text {-mass }\left(\operatorname{species}_{1}, \operatorname{tank}_{R^{\prime}} t_{p t}\right)
\end{aligned}
$$

Equation F.2 expresses the fact that the total mass transferred from the source tank must be equal to the total mass transferred to the receiving tank. Equations F.3, one for each of the $N_{3}$ species in the contained liquid, express the fact that the masses of each of the component species must also be conserved. Equation F.2 can be obtained from. equation $F .3$ by summing both sides of the equations over the components. In the ideal mass transfer model no allowances are made for reactivity among the constituents or leaks occurring during transfer.

The differential form of the ideal mass transfer constraint

$$
\begin{gathered}
\left.\frac{d}{d t} \text { mass (contained-liquid, tank }, t\right) \\
= \\
-\frac{d}{d t} \operatorname{mass}\left(\text { contained-liquid, tank } k_{R}, t\right)
\end{gathered}
$$

can be obtained by replacing the algebraic form of equation F.2 with its differential counterpart. Equation F.4 expresses the fact that the rate of mass transfer into the receiving tank must be equal in magnitude and opposite in sign to the transfer of mass out of the source tank. 
APPENDIX G: MEASUREMENT MODELS

The measurement model describes the relationship between the observed measurement variables and the process state variables. The measurement model consists of two major components, the deterministic transformation describing the ideal behavior of the observing device in terms of the process state variables and the measurement error model that describes deviations from that ideal behavior. Mathematically, this can be written as:

$$
z_{1}=f_{1}\left(x_{1}, x_{2}, \ldots, x_{n}\right)+e_{1}
$$

where $f_{i}\left(x_{1}, x_{2}, \ldots, x_{m}\right)$ represents the deterministic aspects of the transformation of the system state performed by the measuring device and $e_{1}$ represents the measurement error. The measurement error, $e_{i}$, may consists entirely of random error, in which case it is described by its probability distribution, its temporal correlation, and its correlation with other random variables in the system. In many cases a suitable approximation for $e_{i}$ is to assume that it is zero mean, white Gaussian noise that is uncorrelated with the other measurement errors and is also uncorrelated with the process noise. Additional structure may be imposed on the error model, if required. For example, temporal drift of a sensor can be represented by writing the error as the sum of the random term and a polynomial bias term, in which the constants of the polynomial are assumed to be constant, but unknown a priori, i.e.,

$$
e_{1}=\left(b_{0}\right)_{1}+\left(b_{1}\right)_{1} * t+\left(b_{2}\right)_{1} * t^{2}+n_{1}
$$

where $\left(b_{j}\right)_{i}, j=1,2,3$ are constant but unknown parameters and $n_{i}$ is random additive noise.

The form of $f_{i}$ depends on the sensor in question and the choice of the process state variables. A complete listing of the sensed variables for the Pilot Vitrification Project is given in Appendix A. In this section we will give the derivation of the expression for $f_{i}$ for the Holledge Level Detector and the ICP concentration measurements.

\section{G.I Holledge Level Detection system}

The Holledge level detection system is designed to monitor tank level and simulated slurry density. The operating principle is similar to that of a standard dip tube bubbler system. Dip tube bubblers bleed a small flow of air out a set of tubes into the fluid. The tubes are set at different known heights in the fluid which causes a change in the pressure on the air flowing into each individual tube. The differences in pressures are converted into a level measurement as shown below. 
In what follows, the height of a tube refers to the height of the terminus of the tube; for example, "the lowest tube" is shorthand for "the tube with. its terminus nearest the bottom of the tank. Assume there are three pressure measurement tubes in the system, with subscript 0 associated with the lowest (reference) tube, subscript 1 associated with the midale tube, and subscript 2 associated with the upper tube. The termina of reference and middle tubes are in the slurry, while the terminus of the upper tube is in the headspace above the slurry.

Let the pressure measured at the terminus of the tube, $i=0,1,2$, be given by $P_{i}$ and let $\Delta P_{i} \equiv P_{0}-P_{i}$, denote the difference between the pressures measured at the reference tube and tube $i, i=1,2$. Denoting the known tube heights, $h_{0}$ and $h_{1}$, as the distance from the terminus of the reference tube to the bottom of the tank and the terminus of the middle tube, respectively, and the unknown distance from the top (surface) of the slurry to the to the terminus of the reference tube, the total depth of the slurry, from the bottom of the tank to the top of the slurry, $h$, is given by $h=h_{0}+h_{2}$. The total pressure measured in each tube is equal to the sum of the air pressure and the pressure exerted by the fluid:

$$
\begin{aligned}
& P_{0}=\operatorname{air} \text { pressure }+\rho g h_{2} \\
& P_{1}=\operatorname{air} \text { pressure }+\rho g\left(h_{2}-h_{1}\right), \text { and } \\
& P_{2}^{i}=\text { air pressure, }
\end{aligned}
$$

where $\rho$ is the density of the slurry, which is assumed to be homogeneous and $g$ is the gravitational constant.

Using the expressions for the total pressures in the expressions for the pressure differences, the pressure differences can be expressed in terms of the tube heights as

$$
\Delta \mathrm{P}_{\mathrm{i}}=\rho g \mathrm{~h}_{\mathrm{i}}
$$

Since $h_{l}$ is known, the density can be estimated from the measured pressure difference between the middle tube and the reference tube:

$$
\rho=\Delta p_{1} / g h_{1}
$$

The density estimate given by (G.4) can be used to estimate the unknown height of the slurry above the terminus of the reference tube:

$h_{2}=\Delta P_{2} / \rho g=\left(\Delta P_{2} / g\right)(1 / \rho)=\left(\Delta P_{2} / g\right)\left(g h_{1} / \Delta P_{1}\right)=\left(\Delta P_{2} / \Delta P_{1}\right) h_{1}$

Substituting this expression for $h_{2}$ in terms of the measured quantities $\Delta \mathrm{P}_{1}$ and $\mathrm{P}_{2}$ and the known distance $h_{1}$ into the expression relating the slurry depth to $h_{0}$ and $h_{2}$, it can be shown that the 
slurry level can be related to the pressure measurements and the known tube heights by:

$$
h=h_{0}+\left(P_{2} / P_{1}\right) h_{1}
$$

Using the definition of density as the ratio of mass, $M$, to volume, $V$, the mass of the tank can be expressed as:

$$
M=\rho V
$$

Assuming the tank is cylindrical with cross-sectional area, A, the volume of the tank can be expressed as

$$
\mathrm{V}=\mathrm{A} * \mathrm{~h}
$$

substituting (G.7) into (G.6) leads to:

$$
\mathrm{M}=\rho \mathrm{Ah}
$$

substituting the density estimate (G.4) and the slurry level estimate $(G .5)$ in $(G .8)$ results in:

$$
M=\left(\Delta P_{1} / g h_{1}\right) A\left[h_{0}+\left(P_{2} / P_{1}\right) h_{1}\right]
$$

Simplifying (G.9) yields an expression for the mass estimate in terms of measured quantities and known constants:

$$
M=(A / g)\left(\Delta P_{1} / h_{1}\right)\left[h_{0}+\left(P_{2} / P_{1}\right) h_{1}\right]=(A / g)\left(\left(h_{0} / h_{1}\right) \Delta P_{1}+\Delta P_{2}\right)
$$

An early problem encountered by the Defense Waste Processing Facility (DWPF) with the Holledge system was the calibration of these instruments. The pressure response of Holledge sensors varies directly with temperature. That is, if the liquid level is held constant and temperature is increased, the instrument will indicate an increase in the liquid level. Temperature calibration of the Holledge Level Detection system based on data received in the first quarter of 1992 is discussed in [McKay and Beckette, draft].

\section{G.2 Inductively coupled plasma(ICP) concentration Heasurements}

Plasma emission techniques determine atomic species in a sensitive, selective, and easy-to-use manner. The ICP is an electrodeless argon plasma operated at atmospheric pressure and sustained as a plasma by inductive coupling to an $r-f$ electromagnetic field. The plasma source causes excitation of the sample atoms. Radiation, emitted as characteristic narrow lines by the excited atomic species, is separated by a high resolution dispersion system. The intensity of the resolved analytical line is determined by a detector and is proportional to the concentration (weight per unit volume) of a particular species in solution. A thorough discussion 
of ICP can be found in' [Fassel, 1978].

The technique measures the concentration of metallic cation. Therefore the ratio, $r_{i}$ of the concentration of oxide, $\left(c_{i}\right)^{\circ}$, to the measured concentration of cation, $\left(c_{i}\right)^{+}$, must be known:

$$
r_{i}=\left(c_{i}\right)^{0} /\left(c_{i}\right)^{+}
$$

for each species in the slurry. Furthermore, the process state variable, oxide mass, $\left(m_{i}\right)^{\circ}$, is the product of the oxide concentration and sample volume:

$$
\left(m_{i}\right) \cdot=\left(c_{i}\right)^{\circ} * V_{s}
$$

Therefore the relationship between measured variable, $\left(c_{i}\right)^{+}$, and state variable, $\left(m_{i}\right)^{\circ}$, can be written as,

$$
\left(c_{i}\right)^{+}=\left(m_{i}\right)^{\circ} /\left(r_{i} * v_{s}\right)=\left(m_{i}\right)^{\circ} / \alpha_{i \prime}
$$

where

$$
\alpha_{i}=r_{i} * v_{s}
$$

is assumed known for each species in the slurry. The ICP oxide measurements are therefore linear in the oxide mass when this constant is known. 
APPENDIX H: FPTS MONTTORED VARIABLES

Approximately 70 process variables are monitored throughout the process, mostly temperatures, pressures and flow rates. A summary of the available measurements is given below. Numbered. categories are organized by data type. Within each category, the FPTS equipment for which that data type is monitored are listed.

1. Voltage (VAC), Current(AMP), Speed (RPM)

Agitator (AG-1000)

Sample pump (P-1002)

Transfer-pump (P-1101)

2. Flow (GPM)

Condensate

Transfer TK-900 to $\mathrm{HB}-15$

Transfer $\mathrm{HB}-13$ to $\mathrm{HB}-15$

Formic acid addition flow

Steam supply (HB-15 heating coils (E-1001, E-1002))

Cooling water (E-1003)

Hydragard sampler

Sampler flush water

Melter feed line

Feed recycle loop

Condenser cooling water

Offgas

Auxiliary offgas

3. Iriquid Level

$\mathrm{HB}-14$

$\mathrm{HB}-15$

4. Specific Gravity

HB-15 MFT

HB-15 SRAT/SME

5. Weight

TK-900

$\mathrm{HB}-15$

5. Pressure

$\mathrm{HB}-15$

HB -15 head space

HB-15 purge air

Sample pump discharge

Hyrdogard sampler discharge

Feed recycle loop

Steam header

E-1001, E-1002 steam Supply

E-1001 coil condensate

E-1002 coil condensate

E-1003 coil inlet 